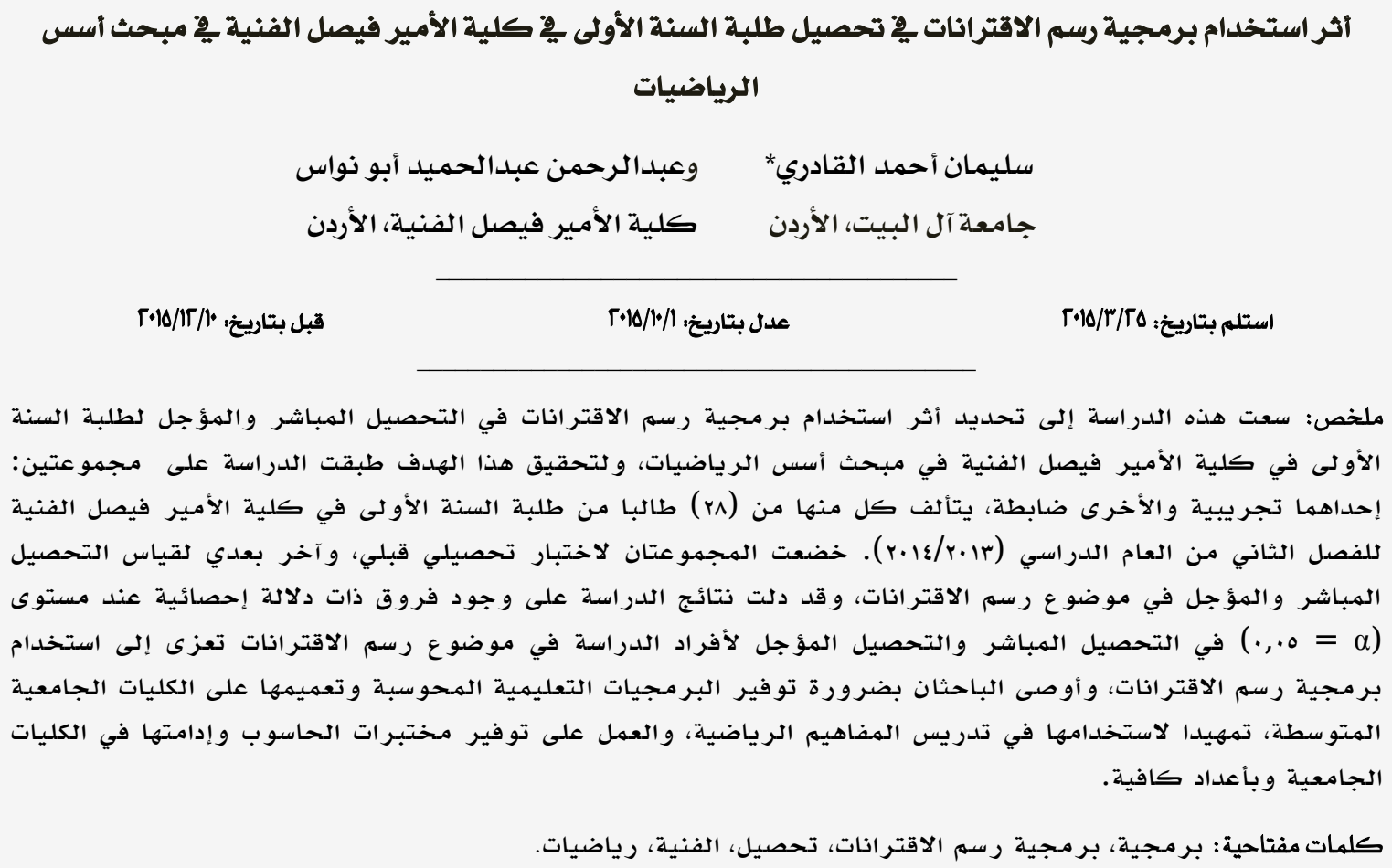

\title{
The Effect of Using Graphing Functions Software on the Achievement of the First-Year Students at Prince Faisal Technical College in Basic Mathematics
}

\author{
Suleiman A. Alqadere* \\ \& Abdelrahman A. Abunawwas \\ Al Al-Bayt University, Jordan Prince Faisal Technical College, Jordan
}

\begin{abstract}
The purpose of this study was to investigate the effect of using the Online Graphing and Functional Plotter software on the achievement of the first-year students at Prince Faisal Technical College (PFTC) in basic mathematics. To achieve this goal, subjects from the first-year students at PFTC of the educational year $(2013$ / 2014) was divided into the experimental and control groups with (28) students each. The two groups underwent pretest and posttest in the subject of functional plotting. The results of the study revealed that there was a statistically significant difference at $(p<0.05)$ between the groups on the postmathematics achievement test scores in favor of the experimental group. The researchers recommended providing the colleges with the computerized educational software in preparation for use in teaching, and working on sustainability of computer labs at colleges in sufficient numbers.
\end{abstract}

Keywords: Software, graphing functions software, achievement, technical, mathematics.

*alqadere@aabu.edu.jo 
يعد الحاسوب التقنية الأكثر تحديا للعاملين في

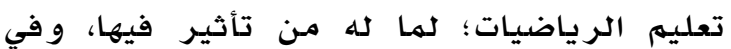
طر ائق تدريسها؛ و لهذا استرع اهتمام التربوين وظهرت بر امهج حاسوبية مختتلفة، بهدف تحسين فرص تعليهم وتعلهم الرياضيات من خلال استخدام الحاسوب كوسيلة تعليمية، وقد تجلى هذا التوجه في استثمار الحاسوب و إمكاناته و بر امجهـ في تعليهم المفاهيم الرياضية المـجردة، من خلال

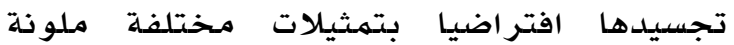
و ثلاثية الأبعاد، ما أسهم في تنمية قدرات المتعلمين على حل المسألة الرياضية، وزاد من مستوى تحصيلهم العلمي هي الرياضيات، و أكسبهم مهارات أسساسية متتنوعة، مثل الدقة و الإتقان و التر تيب (Wei \& Ismail, 2010). لأهمية الحاسوب والتقنيات والوسائط المتعدددة المتعلقة به في تعلهم الرياضيات وتعليهـها، فقد

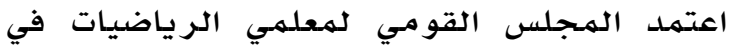

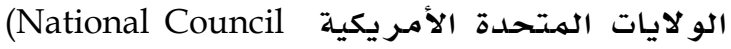
مبدأ of Teachers of Mathematics-NCTM) التكنو لوجيا كأحد المبادئ التي تقوم عليها

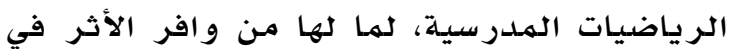
تحسين تعلم الطلبة، و تسهيل تنظيهم وتحليل البيانات و القدرة على القيام بـالعمليات بدقة بـات

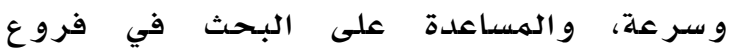
الرياضيات كافة (NCTM, 2000). تعاظم استخدام الحساسوب وبرمجياته في تعليم الرياضيات، واستقصى الباحثون في تعليم الرياضيات أثر عدد منها في إحداث تغيير في طرق تدريس الرياضيات أو تطوير مناهجها، و آثارها الإيجابية على الهعلم والمتعلهم على حد سواء (NCTM, 2008) فاستخدام الحاسوب الجابـ في تعليهم الرياضيات من خلاءل البر مـجيات التعليمية الجيدة يزود المتعلهم بزخم هائل من التفاعل الحقيقي مـع مهمات التعلهم أثناء عملية تعلهم الرياضيات، تفوق أي وسيلة تعلمية أخرى،

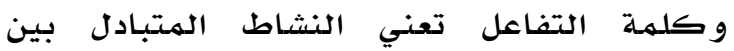
المتعلهم و البرمجية الرياضية؛ ويقصد بالتفاعل هنا المشاركة المباشرة المستمـرة في اتجاهين؛

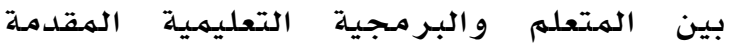

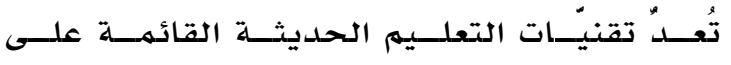
استخدام الحاسـوب ركنّا أساسـيًا مسن أركـان

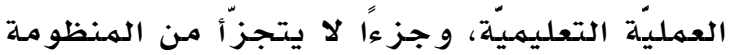

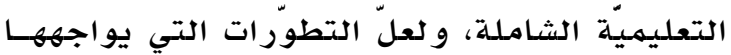
العاله هذا اليوم في جميع ذواحي الحيـاة تجعـل

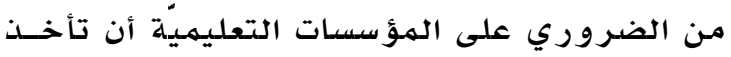

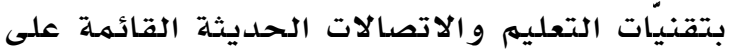
استخدام الحاسوب، من أجل تحقيق أهدافها وفـق المنظو مـة التعليمية. كها تُعدُ بر مـجيّات الحاسوب التعليميّة مـن أبـرز

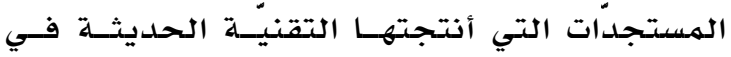

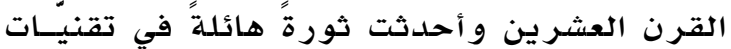

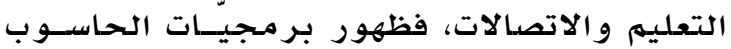
التعليميّة فرض كثيرًا من المتغيّرات في جميـيـع

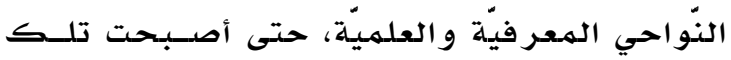

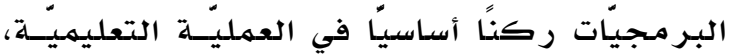

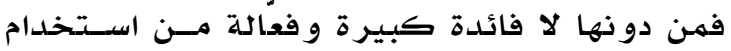
الحاسوب في التعليم (الشر هان، ب...r). بما أن" علم الرياضيَات مرتبط بالحياة العامـة من

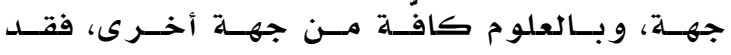

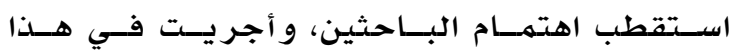
الهـال دراسـات عديدة، و على الر غم مـن الدر اسـات

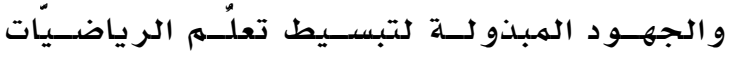

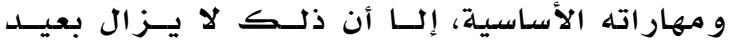

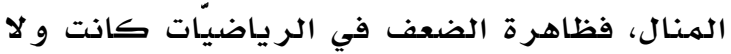

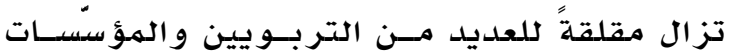

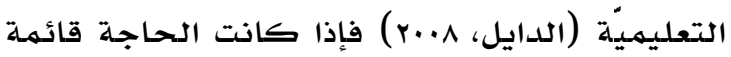

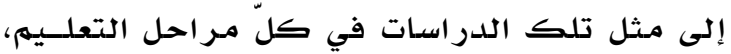

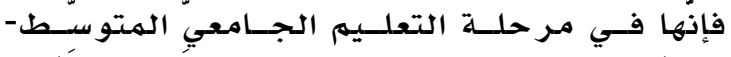
خاصتة مـرحلة السنة الأو لى (المباحث الأساسيّة) -

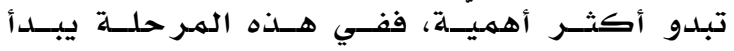

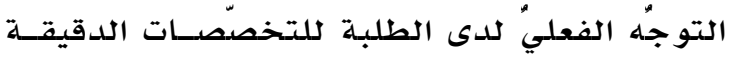

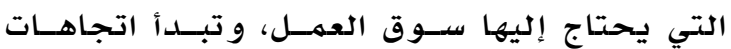

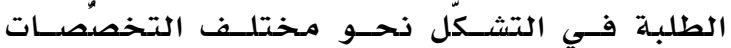

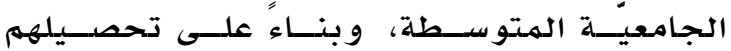
العلهـي فـي مباحسث الســنـة الأو لـى الأسـاســيّة

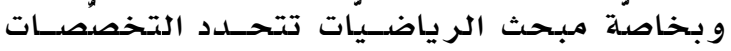
التي سيتو جهون إليها لاحقًا. 
و لتحقيق ذلك فقد اتبعت الباحثة تصميها

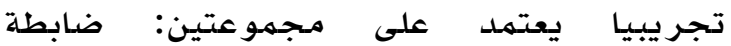

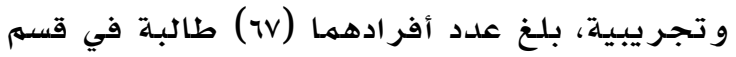

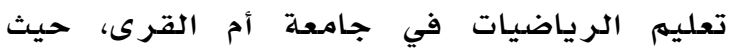

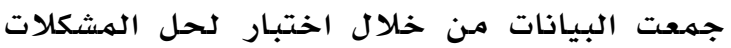

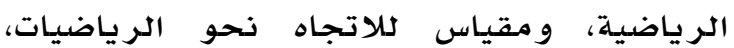

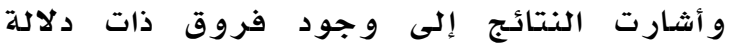

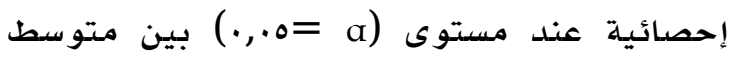
درجات الطالبات اللواتي استخدمن الحاسوب في التتدريب على حل المشكلات الرياضية والاتجاه

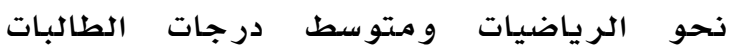
اللواتي لهم يستخدمنه لصالح الطالبات الدلاتي استخدمن الحاسوب.

كما أجرى العبوشي (r..r) دراسـة هدفت إلى

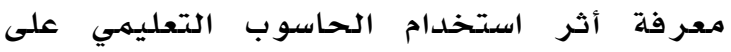

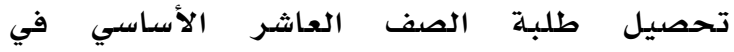
الرياضيات في وحدة الهندسة الفضائية،

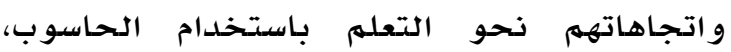

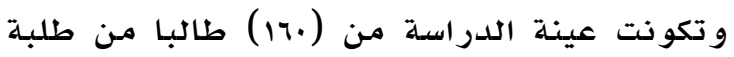
الصف العاشر الأساسي من مدررستي بنات رام الله

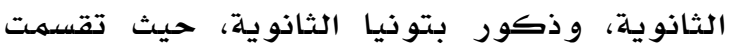
العينة إلى أربع شعب بطريقة عشوائية بسيطة:

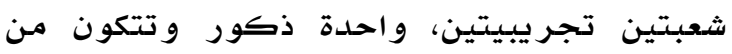

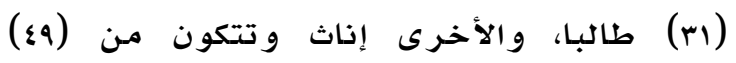

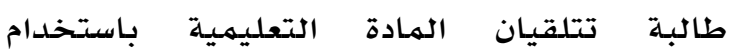
الحاسوب، وشعبتين ضابطتين: واحدة ذ ذكور و تتكون من(rr) طالبا، والأخرى إناث و وتتكون من(£V) طالبة تتلقيان الهـادة التعليمية بالطريقة التقليدي، وبعد و و إيجاد

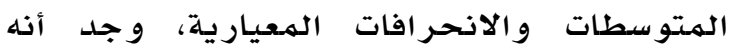
توجد فروق دالة إحصدئية عند مستوى الدلالة

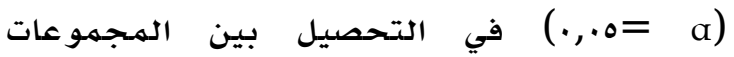

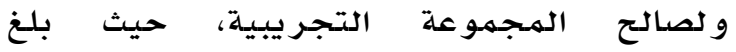

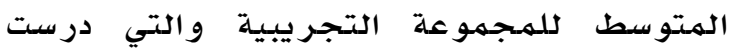

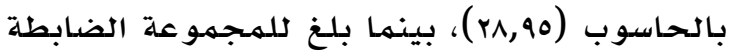

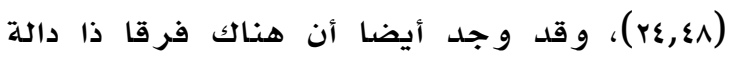

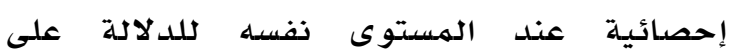
تحصيل الطلبة تعزى للجنس و ولصالح الإناث، و لكن لهم يتبين وجود فروق دالة إحصدئيا في التحصيل تعزى للتفاعل بين طريقة التدريس
بوساطة الحاسوب، متضمنة أنشطة إيجابية من قبل كل من الطرفين (الفار،r...r). تجلدر الإثـارة إلى أن ما يميز التعليم في الكليات

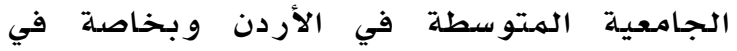
المباحث الأساسية هو التدريب والتهبية التطبيق العملي

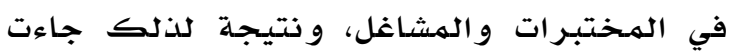
فكرة إجراء هذا البحث التي تقوم على مبدأ

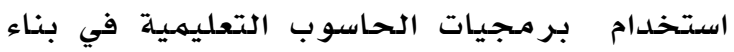

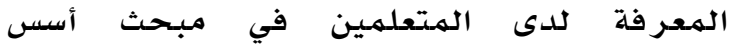

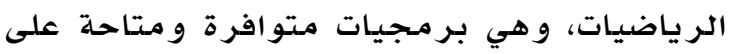

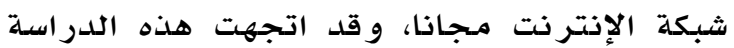

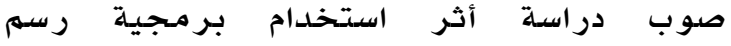

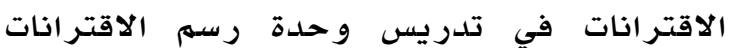
لطلبة السنـة الأولى في مبحث أسس الرياضيات التي يختص بها و يدر سها أحد الباحثين. في ضوء اطلاع الباحثين على الدراسـات والبحوث

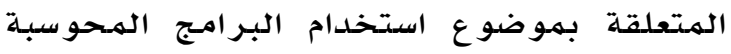
في تدريس مادة الرياضيات- وذذلك من خل خلال

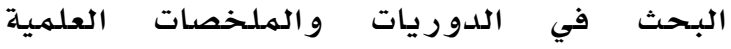

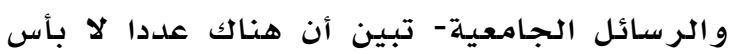

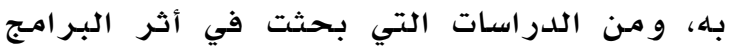

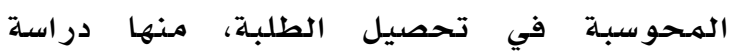

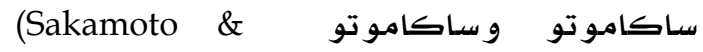
Sakamoto, 1993) العلاقة السببية بين استخدام الحاسوب والإبداع و دافعية التعلهم لدى طلبـة المرحلة الابتدائية في طوكيو، وطبقت على عينة تكونت من (rابr)

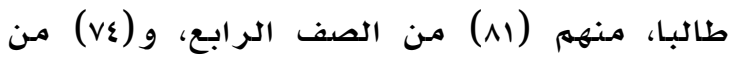
الصف الخامس، و (V7) مـن الصف السـادس، أظهرت نتائج الدراسة عدم وجود علاقة دالة إحصائيا بين استخدام الحاسوب والإبداع، وبين استخدام

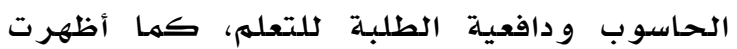
النتائج عدم وجود أثر للخبرة في استخدام الحاسوب في الدافعية للتعله.

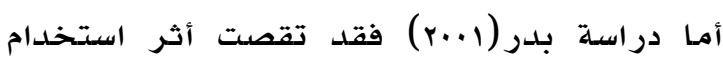
الحاسوب في التدريب على حل المشكلات الرياضية في تنمية قدرة طالبـات قسم الرياضيات

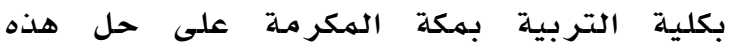
المشكلات وتكوين اتجاه إيجابي نحو الرياضيات، بلهيه 
المجموعة التجريبية من نظير اتهن

المجمهو عة الضابطة.

استخدمت دراسة سيو (SeO, 2008) بر مجية ماث

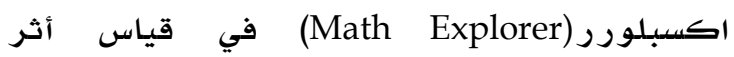

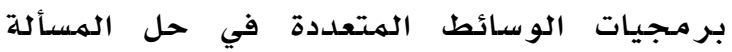
الرياضية الكلامية وتخطي صعوباتها لدى طلبية

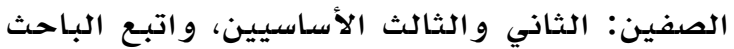

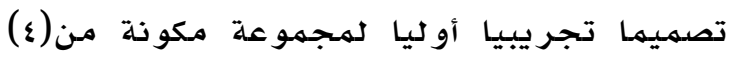

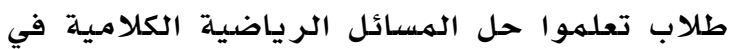

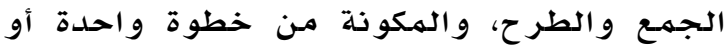

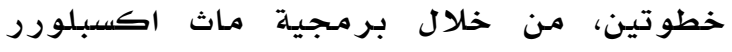
(Math Explorer)

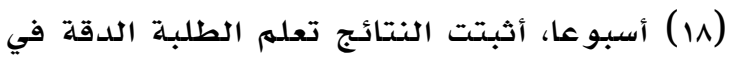

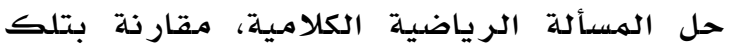
الحلول التي استخدموا فيها الورقة والقلهم.

تقصت دراسـة بوس (Bos, 2009) أثر عناصر

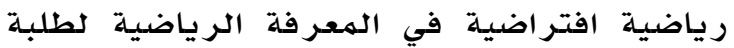
الصف العاشر في ولاية تكساس في الولايات

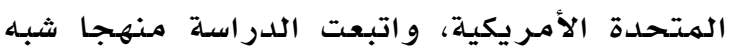
تجريبي، و تضمنـت مجمو عتين: إحداهما تجر يبية

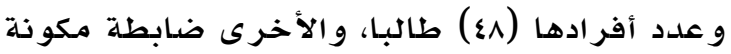

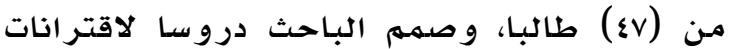
تربيعية لطلبة الصف العاشر باستخدام الآلة الحاسبة الر اسمهة (Graphic Calculators) و بعد الحد

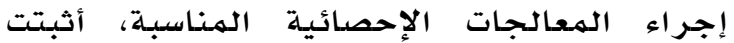

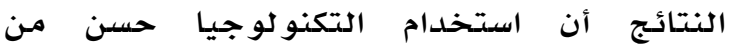
المستوى الأكاديمي للطلبة، وزيادة في قدرتهم على تمثيل المفاهيم الرياضية.

هدفت دراسة هيان و أتسوسي ومانسوره (Haiyan, Atsusi \& Mansureh,2010) أثر ألعاب رياضية حاسوبية حديثة في تحصيل الطلبة في الرياضيات ودافعيتهم نحوها، وشارك

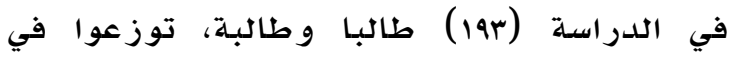
مججموعتين: ضهابطة وتجريبية، وتبنت الدراسلة منهجا كميا شبه تجريبي، بالإضافة إلى مقابلات

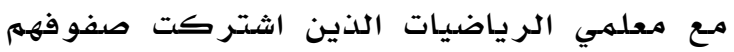
في الدراسلة، وأشارت الدراسلة إلى تفوق طلبـة المجموعة التجريبية التي تعلمت بـاستخدام
والجنس، كما تبين وجود فروق دالة إحصائية

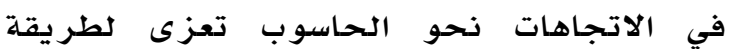

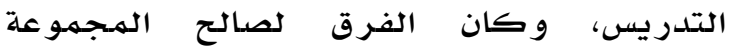
التجر يبية.

استخدمت در اسـة مـانوشهري (Manouchehri, 2004) بر مجية تفاعلية في تعليهم الجبر، لدعم تدريسه في كلية مجتهـع في بوسطن بالولايات المتحدلة

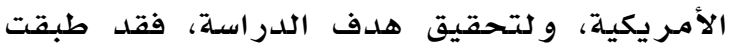
بر مجية ذوكالك (NuCalc) و لمدة ثلاثة أسابيع في تدريس مادة الجبر، وقيست فاعلية البرمجية

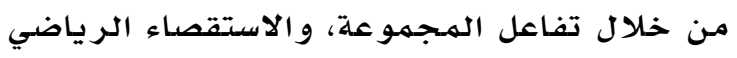

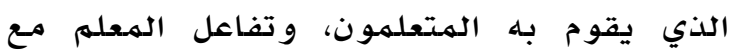
المتعلمين، وبعد استخدام المنهجين: النوعي

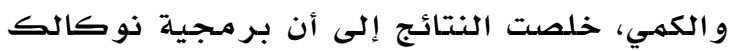
أسهمت كأداة في توسيع التفكير الرياضي لدى إلى الدي

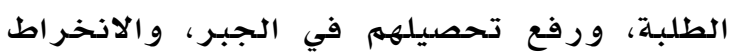

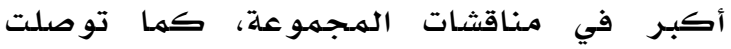
النتائج إلى أن البر مجية أثبتت أنها و وسيلة

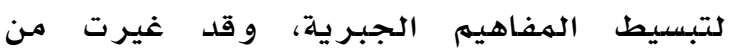
الثقافة الصفية بإحداث التفاعل بين الهعلم

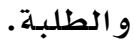
درست عيد (Eid, 2005) أثر استخدام الإنتر نت في

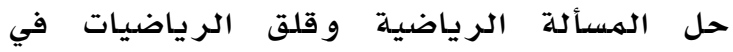
المدارس الأسـاسية في الكويت، مقارنة باستخدام الورقة والقلهم في حل الهسألة الرياضيلة،

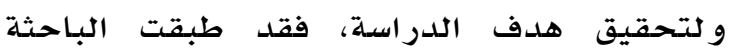
تجربتها في إحدى المدارس الخاصلة في مدينة

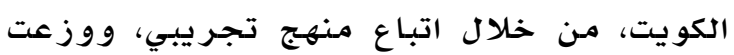

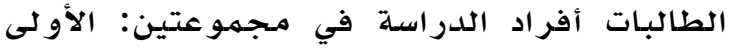

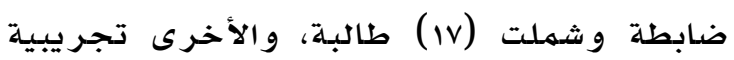
و شـملت (ع) طالبة، وخضعت المهجموعة الضدابطة لاختبار في حل المسألة الرياضية باستخدام

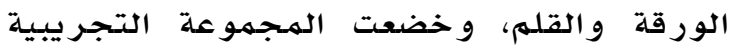

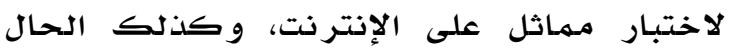
لمقياس قلق الرياضيات، وقد أثـارت النتائج إلى تماتى

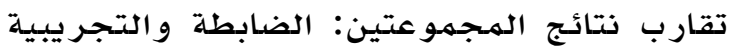
في اختبار حل المسألة الرياضية، ووجود درجـة قلق رياضيات أدنى ودالة إحصائيا لطالبات 
المتخصصة لدى طلبة الكليات الجامعية، و بالأخص الهندسية و الفنية.

تناولت هذه الدراسـة بيان أثر التحصيل المباشر و التحصيل المؤجل، في حين أن أغلب الدراسات

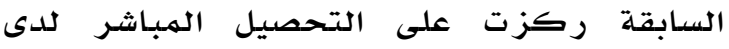
الطلبية.

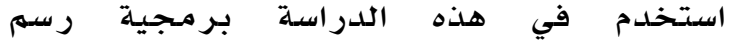

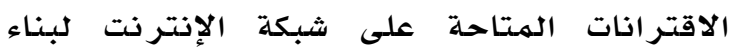
دروس وحدة رسم الاقتر انات، وذلك رغبـة من الباحثين في تشجيع المدرسين والطلبة على الماتى

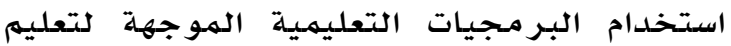
و تعلم الرياضيات الهتاحة على شبكة الإنترنت

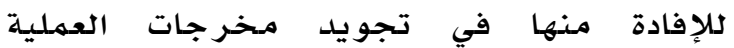

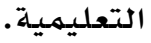

مشكلة الدراسة و أسئلتها

تعد الرياضيات من المباحث العلمية الأساسية

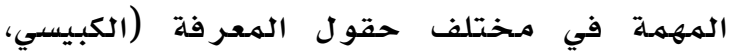
(r..V المبادئ التي تقوم عليها تعليم الرياضيات و تعلمها، وينص هذا المبدأ على ضرورة استخدام التكنولوجيا في تعليم الرياضيات، وعلى رأسها الحاسوب، و البر مجيات التعليمية (NCTM, 2000)، و بالرغم من ذلك فإن أحد الباحثين الذي له

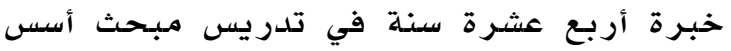
الرياضيات في كلية الأمير فيصل الفنية، ومن خلال مـلاحظته لأساليب معلمي الرياضيات في

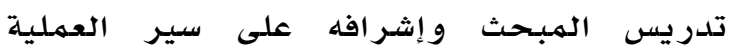
التعليهية كرئيس لقسم الرياضيات لاحظ ضعف استخدام الحاسوب التعليهي والوسائط الهتعدددة المتصلة به في تلدريس الرياضيات، ما يؤدي بالطلبة إلى الشعور بالملل و الصعوبة في فهم بعض المفاهيم والرسومات في الرياضيات و تصور هـا.

كما أن نتائج الدراسـة الدو لية للرياضيات و العلوم ( Trends in International Mathematics (and Science Study-TIMSS 2007 التي أجريت لتقييم تحصيل طلبـة الهدارس و أشرفت عليها The (الربطة الدو لية لتقييم التحصيل التربوي International Association for the Evaluation of
الألعاب الحاسوبية على طلبة المهموعة الضابطة، كما تحسنت دافعيتهم نحو تعلم الرياضيات.

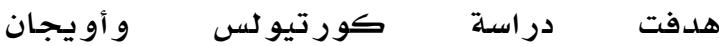
(Kurtulus \& Uygan, 2010) الأنثطة في تتنمية القدرة المكانية التصورية

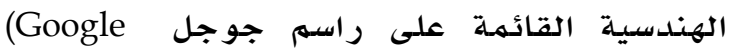
Sketch Up)

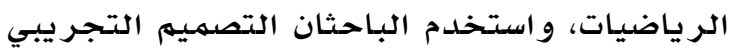
باختبارات قبلية و بعدية، و مجمموعتين: ضرابطة وتجريبية، لذلك فقد درست المـجموعة الضابطة

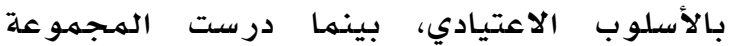
التجريبية من خلال راسهم جوجل لتمثيل الأشكال

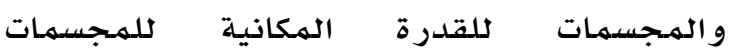

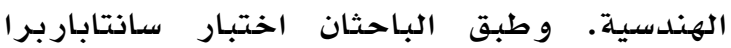

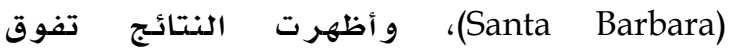

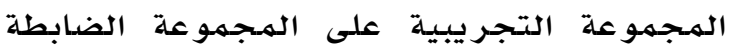
في اختبار القدرة المكانية.

من خلال استعر اض الدراسـات السابقة يمكن الوصول إلى المـلاحظات الآتية:

تناو لت معظم الدراسـات السـابقة فاعلية استخدام

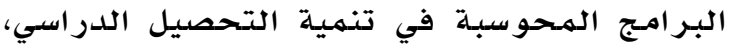

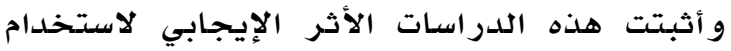

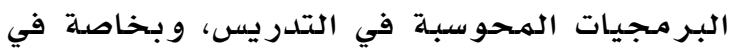
التحصيل الدراسي، باستثنـاء دراسلة ساسكاموتو

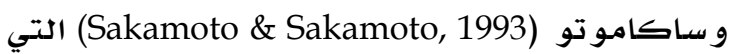
أظهرت عدم وجود علاقة دالة إحصائيا بين استخدام الحاسوب والإبداع، وبين استخدام الحاسوب و دافعية الطلبة للتعله.

تناولت الدراسـات السابقة موضوع التحصيل في

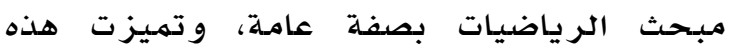

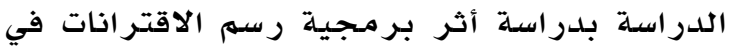
تحصيل بعض المفاهيم الرياضية متمثلة بمهارة رسم الاقتر انات.

سعت هذه الدراسـة لبيان أثر البـرامج الهـحوسبـة

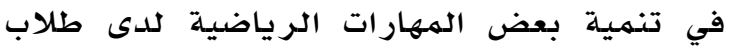

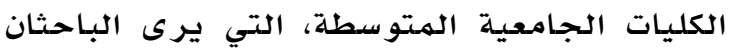

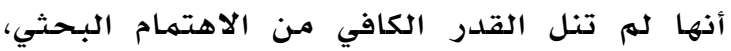

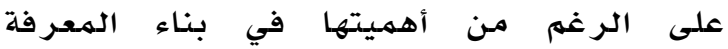




\section{أهمية الدراسة - أهم}

تنبـع أهمية هذه الدراسـة من اتصالها بمبـحث الر ياضيات لما يحتويه من مفاهيه مجر دة يصعب

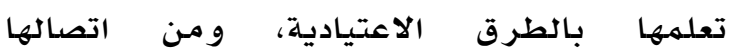
بالبر مهجيات الحاسوبية التي تستطيع تقريب المفاهيم الرياضية المجردة إلى الهتعلمين من

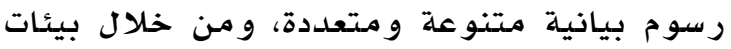
تعلهم افتر اضية، وتزداد هذه الأهمية في مرحلة التعليه الجامعي، وبالذات في الكليات الهندسية ودية

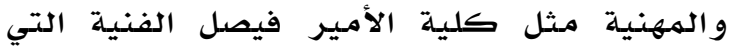

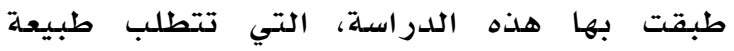
تخصصاتها دقة عالية في مهارة الرسه، كها في مباحث الهندسي .(AutoCAD)

كما تكمن أهمية الدراسة في أهمية الموضوع

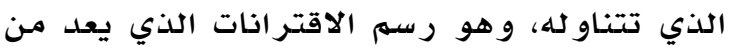

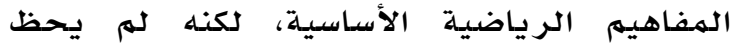
بالاهتمام الكافي في البحوث السابقة، وقد تفيد

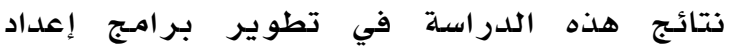
مدرسي مبحث الرياضيات في الكليات الجامعية و تلدريبهم، وقد تههد نتائج هذه الدراسة اسلة لإجراء مزيد من البحوث المتصلية بهذا المجال مستقبلا.

حدود الدراسة و مححدداتها

\section{تحلد نتائج هذه الدراسة بالمحددات الآتية:}

$$
\begin{aligned}
& \text { طبقت الدراسة في الفصل الدراسي }
\end{aligned}
$$

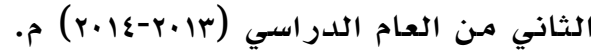

$$
\begin{aligned}
& \text { اقتصرت الدراسة على الوحدة العاشرة }
\end{aligned}
$$

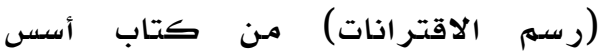

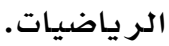

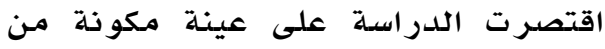

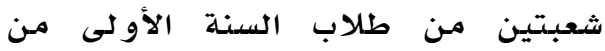
كلية الأمير فيصل الفنية في عمان.

اقتصرت الدراسـة على اختبار تحصيلي من إعداد الباحثين، ولذلك تتوقف دقة الديك

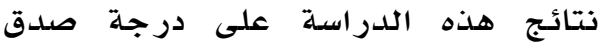
الاختبار و دقته وثباته.
Educational Achievement-IEA

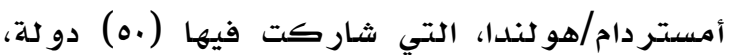

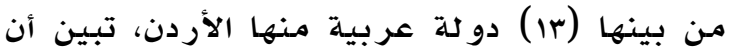
مستوى الأداء في الرياضيات لطلبة الأردن دون

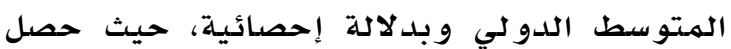

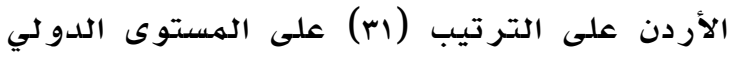

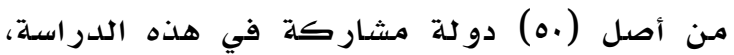

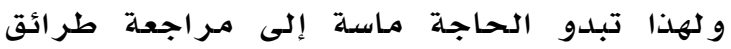
تلدريس الرياضيات، و واستخدام أحدث التدله التقنيات الحاسوبية لارتقاء بمستوى أداء الطلبـة إلى إلى المستوى العالمي (أبو لبدة، V...V).

علاوة على ذلك فإن طريقة تدريس مهارة رسم

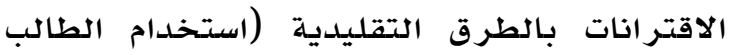
القلم و المسطرة للرسم على ورقة الرسهم البياني

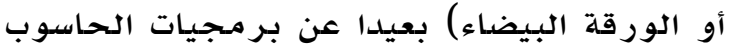

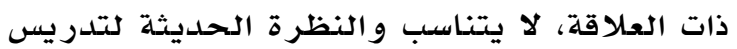

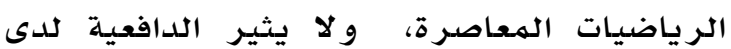

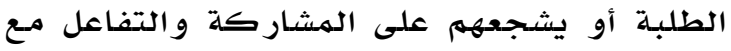
المحتوى التعليمي لمبحث أسس الرياضيات، وومن لهن هنا سعت هذه الدراسة لاستقصداء أثر استخدام بر مجية رسم الاقترانات في التحصيل المباشر و المؤجل في مبـحث أسس الرياضيات لدى طلبـة السنة الأولى في كلية الأمير فيصل الفنية في في في الأردن.

مما سبق يمكن تلخيص مشكلة الدراسة بالسؤ الين الآتيين:

السؤال الأول: هل يوجد فرق دال إحصائيا عند

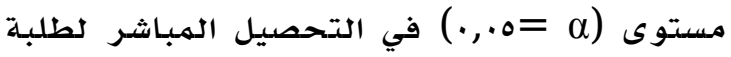
السنـة الأولى في وحدة رسم الاقتر انات يعزى إلى

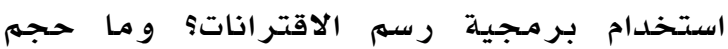
الأثر إن وجدى الند السؤال الثاني: هل يوجد فرق دال إحصائيا عند

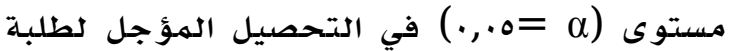

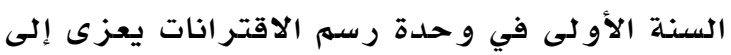

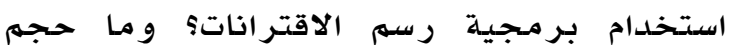

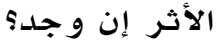




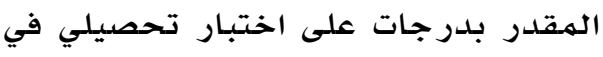

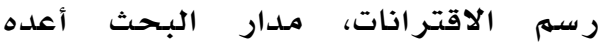

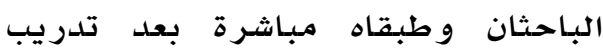
أفر اد عينـة الدراسـة على رسهم الاقتر انات، ويقاس إجرائيا بالعلامـة التي يحصل

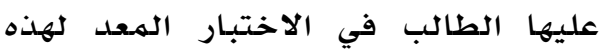

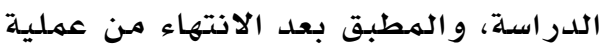

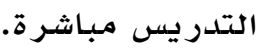

التحصيل المؤجل: مجرموع الخبرات

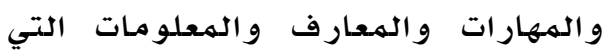
تكونت لدى الطالب، وتشير إلى إنجازه المقدر بلدرجات على اختبار تحصيلي في إلى إلى

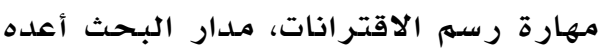

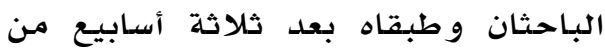

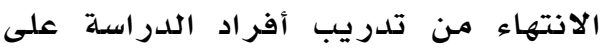

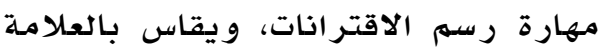
التي يحصل عليها الطالب في الاختبار

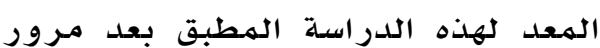
ثلاثة أسـابيع من انتهاء عملية التدريس. طلبة السنـة الأولى: طلبـة الكلية

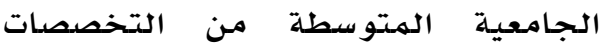
العلمية كافة، الذين يلتحقون بهذه

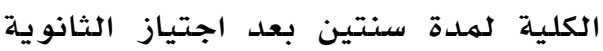
العاملة، فيحصلون على درجة الدبلوم بعد اجديل نجاحهم في الامتحان الشامل.

عينة الدراسة طبقت الدراسـة على عينـة عشوائية عنقودية تألفت من شعبتين بلغ عدد أفرادها (7ه) طالبـا من طلبة السنة الأولى في كلية الأمير فيصل

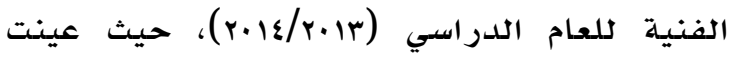

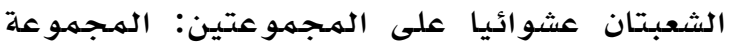

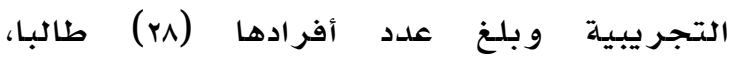

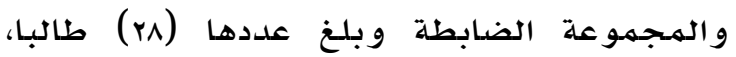
علما بأن طلاب كلية الأمير فيصل الفنية الذين يدرسون مبحث الرياضيات كمقرر أساسي الاسير جميعهم من الذكور ومـن الفئة العهمرية نفسها،

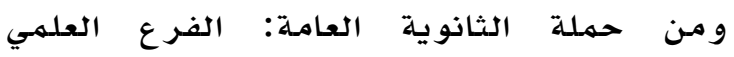
و الصناعي، وذذك بسبب شروط قبولهم في الكليـة.
تعتمد دقة نتائج الدراسة على درجة صدق الاختبار التحصيلي المستخدم فيه

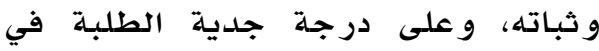

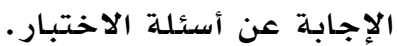

$$
\text { متغير ات الدراسة }
$$

اشتملت هذه الدر اسلة على المتغيرات الآتية:

الهتغير الهستقل: وهو طريقة التدريس، وله

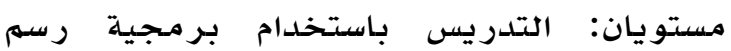
الاقتر انات، و التدريس الاعتيادي.

المتغير ات التابعة: و قد تمثلت بمتغير ين هما:

التحصيل المباشر (الفوري) في وحدة

التحصيل المؤجل في وحدة رسهم

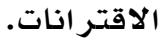

\section{التعريفات الإجر ائية}

بر مسية رسم الاقتر انات: بر نامه

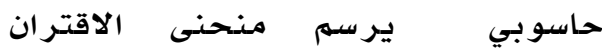
بالاعتماد على إدخال الطالب الهبياشر

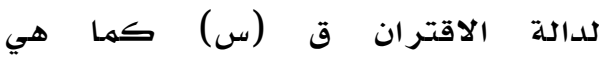
باستخدام لوحة المفاتيح، و لأغر اض هذه

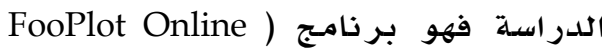
(Graphing and Functional Plotter صمهم البـاحثان شـاشـة استخدامـه من خلال بر نامـ (eXe) eLearning XHTML editor ليكون متاحا للطلبـة بالشكل الذي يناسب العملية التدريسية.

الطريقة الاعتيادية درسم الاقتر انات: هي

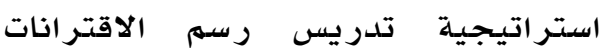

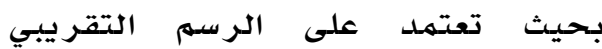

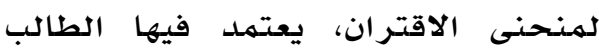

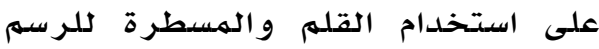
على ورقة الرسم البياني أو الورقة

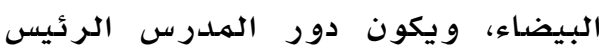
فيها هو الشرح النظري لخطوات الر سهر.

التحصيل الهبياشر: مجموع الخبرات

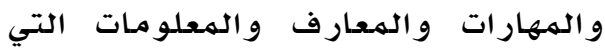
تكونت لدى الطالب، وتشير إلى إنجازه 
مكونات الهحتوى التعليمي بالطريقة

والترتيب اللذين يناسبان أسلوب التقديم

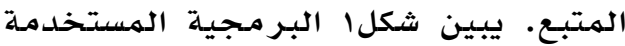

(FooPlot Online Graphing and

من خلال عر مرضها Functional Plotter

$$
\text { بوساطة بر نامج (eXe). }
$$

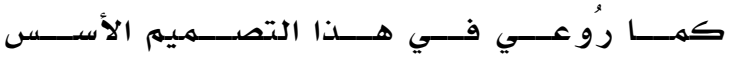

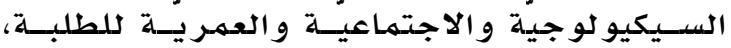
و أسـسس تصـــميهم البـر مـجيــات، مثــل: منـاســـبة

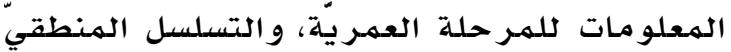
في عرض المعلومات، ومـراعاة الفروق الفرديــة،

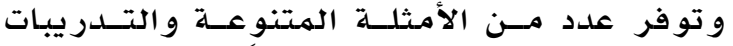

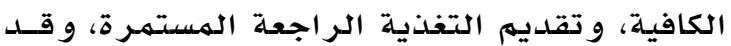
اشتهملت البر مـجيـة علـى شـاشــة عـرض وض وألــوان

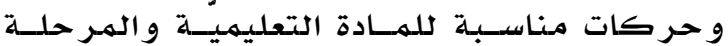

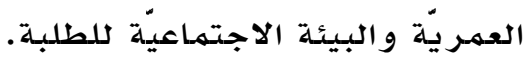

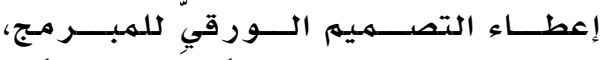

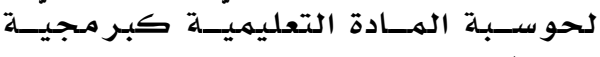

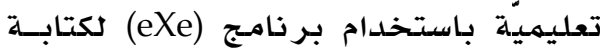

الهادة التعليميَة.
إجر اءات الدراسة

أوثا: مراحل إعداد البرمجية التعليمية

المستخلدمة في الدراسة:

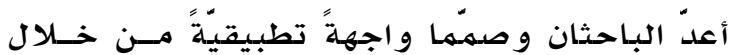

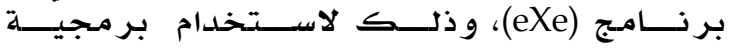

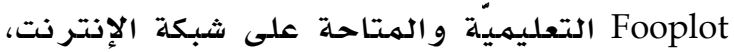

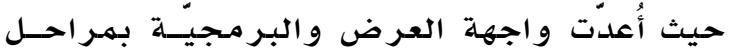
متعددّة على النحو الآتي:

1. مر حللة اختيار المـادة التعليمية:

أعد الباحثان مادة تعليمية من وحدة رسهم

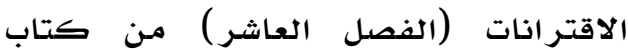

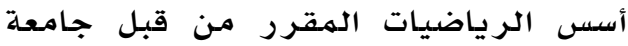
البلقاء التطبيقية لطلبة السنـة الأولى مـن

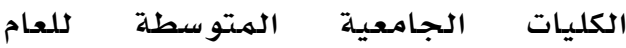

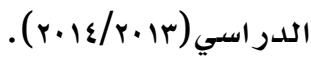

r. عمل تصميم ورقي لعرض البرمجية

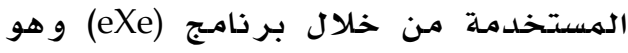
برنامج خاص بتصميهم المحتوى التعليمي الإلكترووني ونشره، ويمتاز بأنه لا يتطلب أي مهارات بر مجهة، ويمكن الناشر مـن بناء

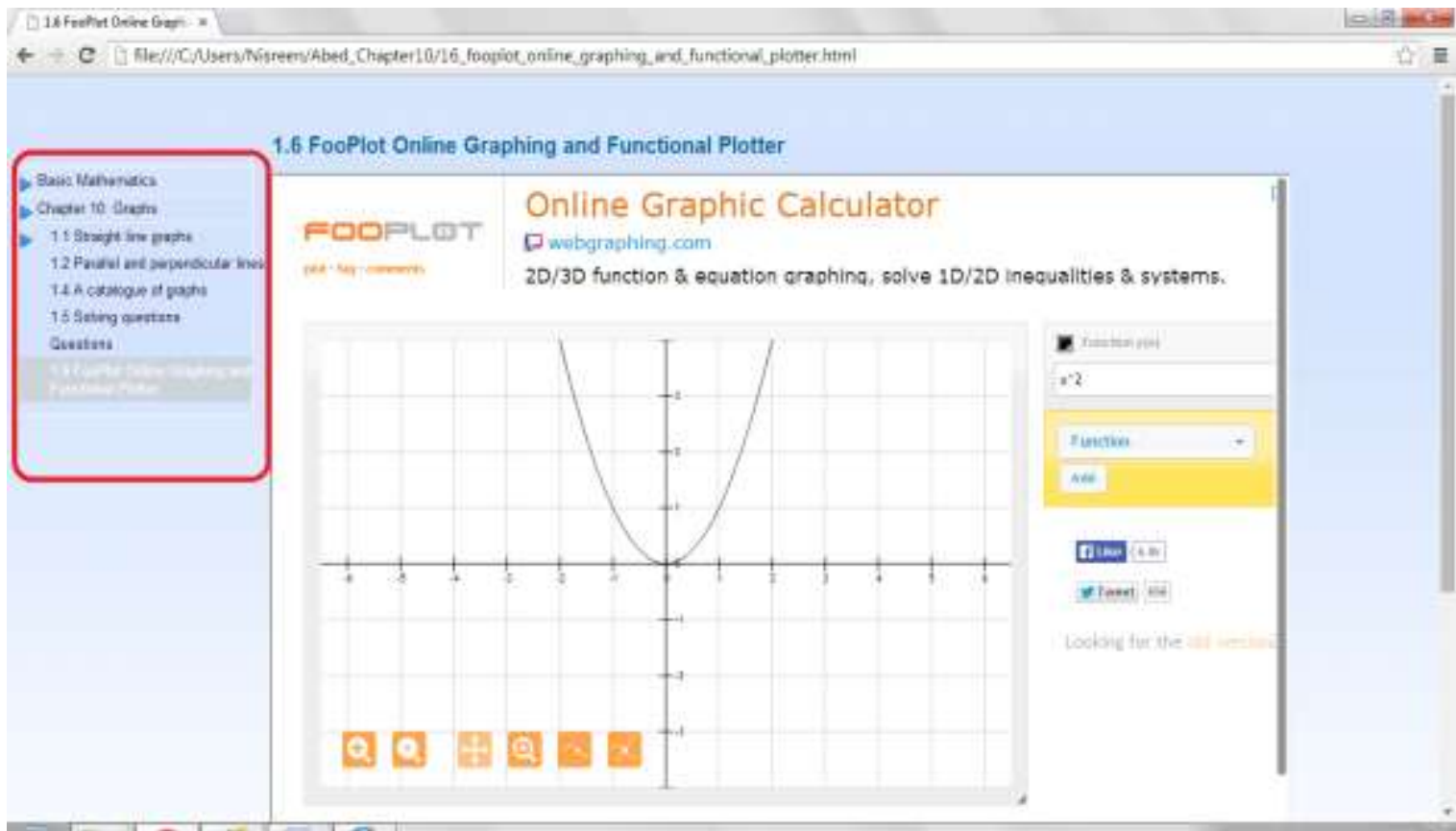

شكل ا: برمجية (FooPlot) من خلال عرضها بوساطة برنامج (eXe) 


\section{r. مرحلة التطبيق:}

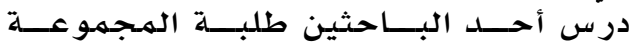

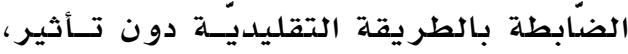

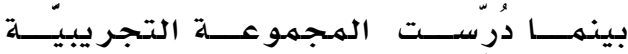

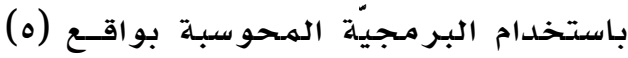

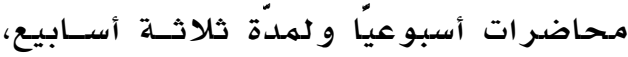

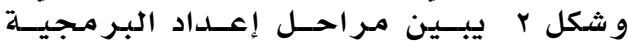

التعليميتة.

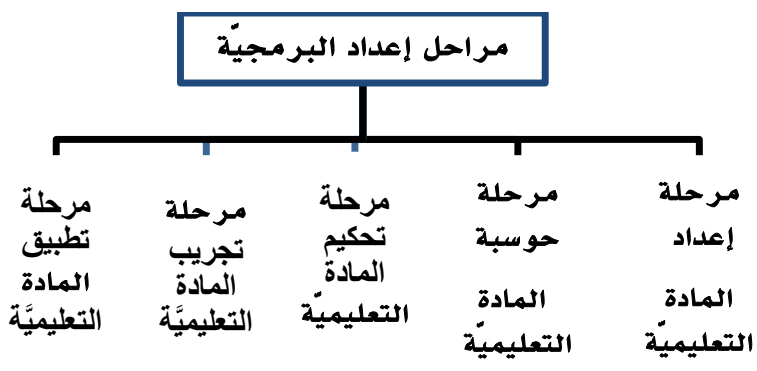

شكل ץ: مخطط مراحل إعداد البرمجية التعليمية

ثانيا: الاختبار التحصيلي المستخدم في الدراسة: لتحقيق أهداف الدراسة، أعد اختبار تحصيلي لقياس تحصيل طلبة السنـة الأولى في وحدة

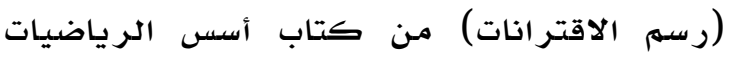

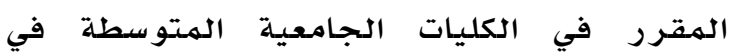
المملكة الأردنية الهاشميلة؛ وذلك لقياس الهيل التعلم

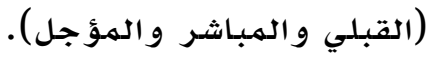

لتحقيق ذذك حلل محتوى الوحدة الدراسية لتحديد الهفاهيم الرياضية التي تتضمهنها، وعينت

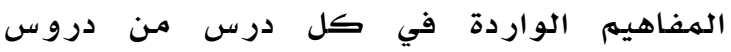
الوحدة، وطورت فقرات الاختبار وفق جدول

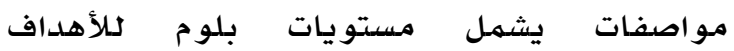

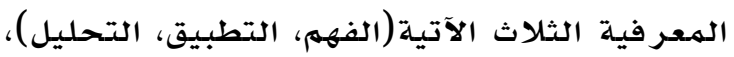
و للمفاهيم الرياضية الواردة في المادة التعليمية.

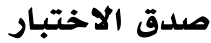

للتأكد من صدق الاختبار عرضده الباحثان على

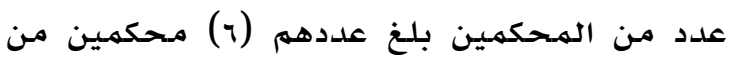

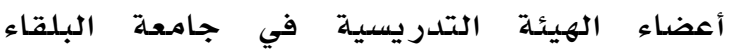

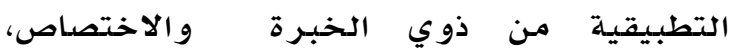
و كذلك مجموعة من المعلمين ذوي الخبرة الطويلة في كلية الأمير فيصل الفنية من مهن مهلة شهادة الماجستير و البكالوريوس في الرياضيات،
بدأت الصـفحة الأولـى بعنــوان الوحسدة

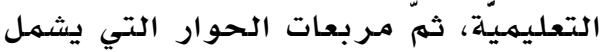

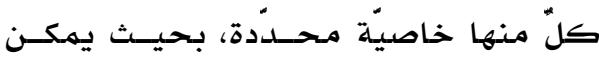

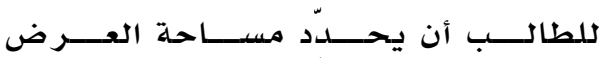
للمســـتوى الـــديكار تي س، ص و لــــون المنحنى للاقتتر ان ومـربع حوار لإمكانيّة رســم منـحنــى آخـر للهســتوى نفســه،

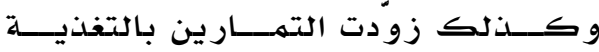
الر اجعة الفوريّة.

عمل ارتباط تشعبي ليسهل الانتقال إلـى

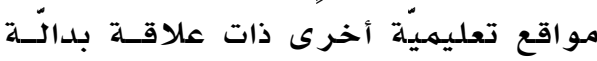
الاقتر ان. - ان

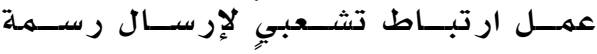
الاقتر ان إلى مدررّ المـادة أو زملائهـ. مرحلة تحكيم البرمجيْة التعليمينة: عُر ضت البر مهيّة التعليميّة علـى خمسـة

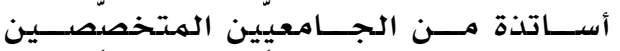

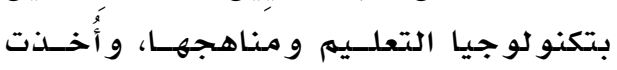

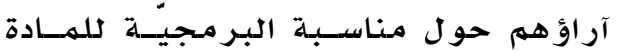

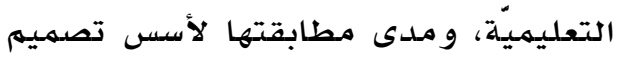

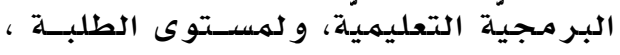

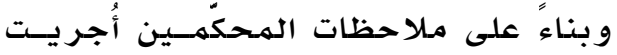

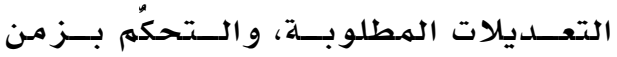

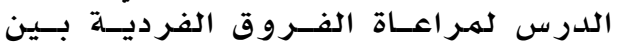
الطلبة، وزيادة الأمثلة و التدر يبـات.

r. مرحلة تجريب البر مـجية:

أُكَّدت صسلاحيّة البر مجيَّة قبـل البــدء بالتطبيق، من خلال تجر يبها علـى عينــة

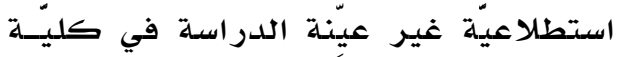
جامعيّة أخرى مشابهة، وذلك للحصدية الكول على التغذية الر اجعة حول مــدى مناسـبـة

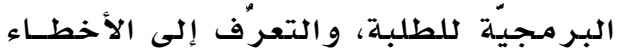

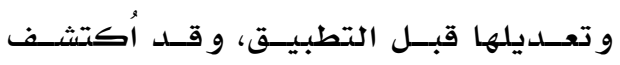
بعض الأخطاء في البر مجريّة و عُدّلت، منها ولها

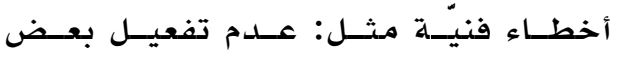

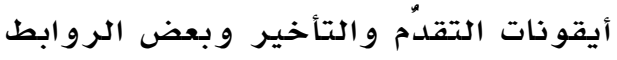

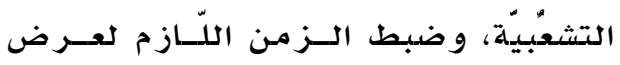

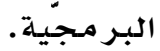

.1 


$$
\begin{aligned}
& \text { و قد بلغ (ع,,•)، و وتعد هذه القيمة مقبولة } \\
& \text { لأغر اض هذه الدر اسـة. } \\
& \text { | الإجر اءات } \\
& \text { من أجل تحقيق الأهداف المنشودة من هذه } \\
& \text { الدرراسة أجرى البـاحثان ما يلي: }
\end{aligned}
$$

1. تحديد مشكلة الدراسلة وأسئلتها

$$
\text { و متغير اتها. }
$$

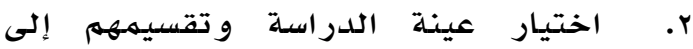

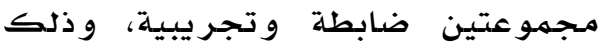
بعد الحصول على موافقة إدارة كلية الأمير فيصل الفنية.

إعداد البرمجية التعليمية، وهي تحضير

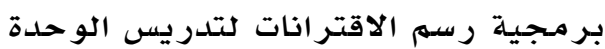

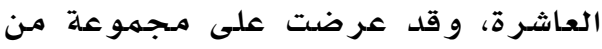

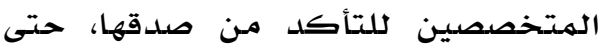
استقرت على صور تها النهائية.

ع. إعداد الاختبـار التحصيلي، من نوع

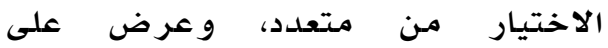
مجمو عة من المحكمين المتخصصين،

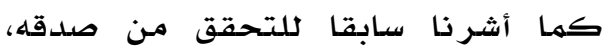
حتى استقر الاختبار بوضعـه النهائي على

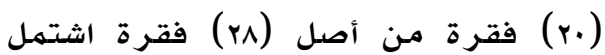

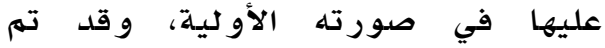

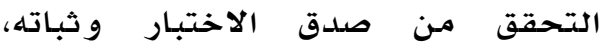
و معامـلات صعو بـة و تمييز فقر اته. ๑. طبق الاختبار التحصيلي على مجمهوعتي

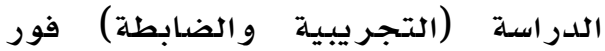

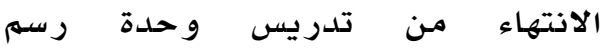

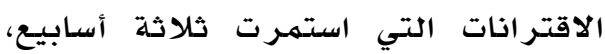

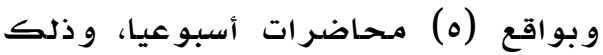

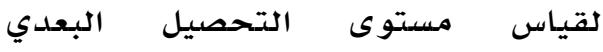

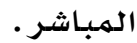

بعد ثلاثة أسابيع أعيد تطبيق الاختبار .7

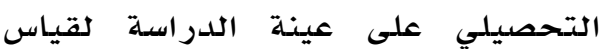
مستوى التحصيل البعدي المؤجل لديهم. V. أجريت التحليلات الإحصائية المناسبة، وجرى التوصل إلى النتائج التي تم
للتأكد من قياس فقرات الاختبار للهدف الذي

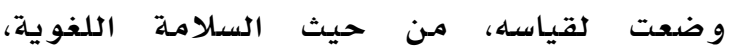

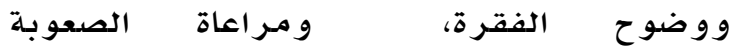

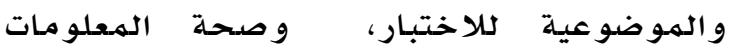

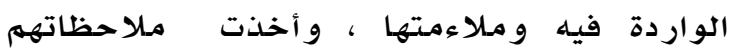

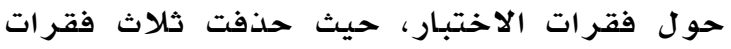
بناء على آراء المحكمين، وحذفت خمس الهس فقرات

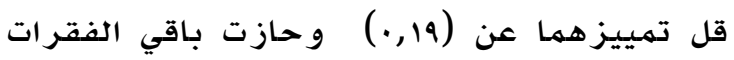

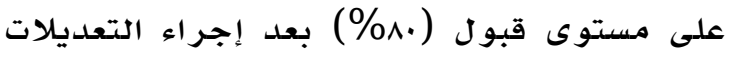

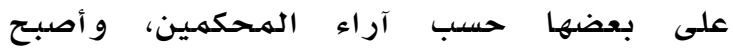

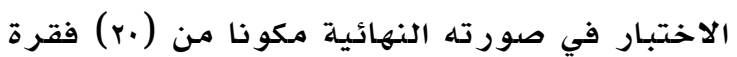
من أصل (rی) فقرة. معاملات الصعوبة والتمييز استخرجت معاملات الصعوبة والتمييز لفقرات الاختبار، وقد تراوحت معاملات تمييز الفقرات

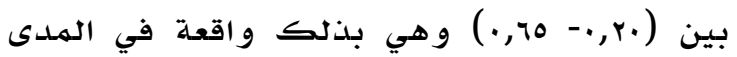

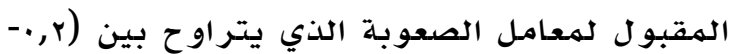

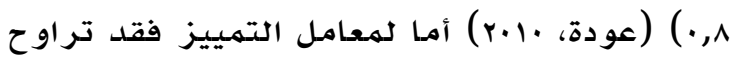

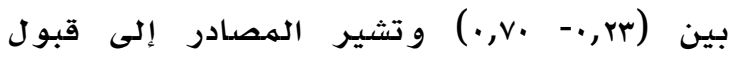

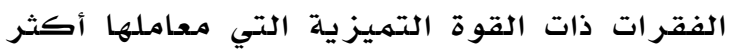

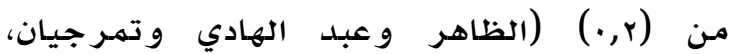
1999). ثبات الاختبار تحق تحق ثبات الاختبار test-) باستخدام طريقة الاختبار و إعادة الاختبار retest

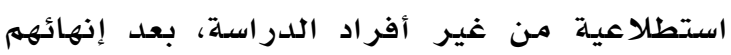

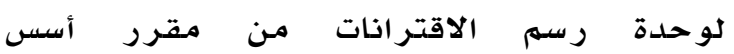

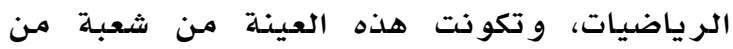

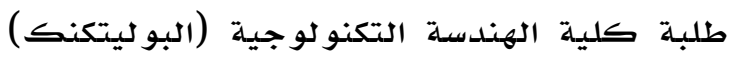
في عمان، التي تتبع جامعة البلقاء التطبيقية

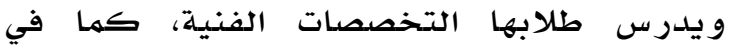

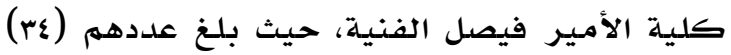

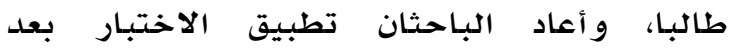

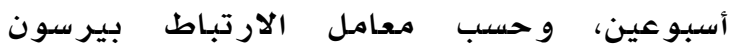
بين التطبيقين: الأول و الثاني، ووكانت (Pearson)

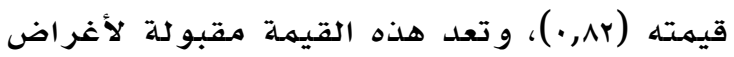

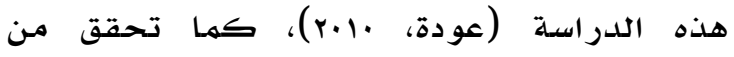

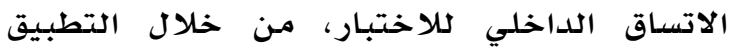

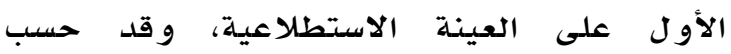
باستخدام معادلة كودر ريتشاردسون (KR-20)، 
درجة من أصل (r. (r) درجة، أي ما نسبته

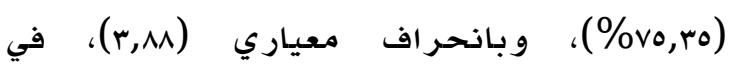

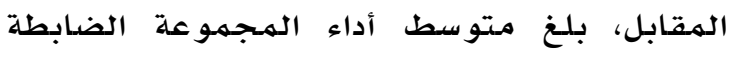

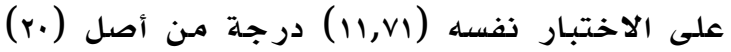

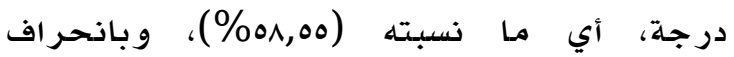

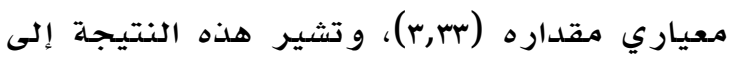

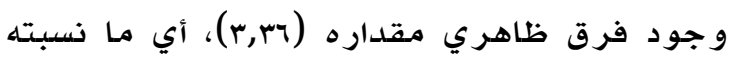

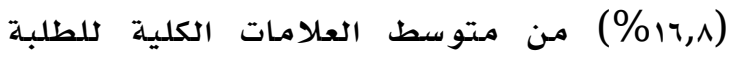

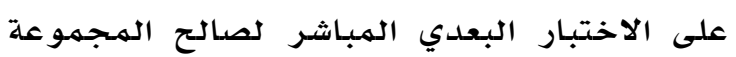

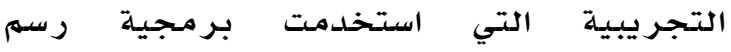
الاقتر انات.

جدول الأبمات المعار

المتوسطات الحسابية والانحرافات المعيارية للعلامات الكلية لأفراد

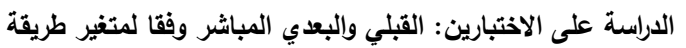
التدريس (الطريقة الاعتيادية، التتريس ببرمجية رسم الاقترانات)

\begin{tabular}{|c|c|c|c|c|c|}
\hline \multicolumn{2}{|c|}{ الاتحراف المعياري } & \multicolumn{2}{|c|}{ 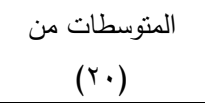 } & \multirow{2}{*}{ الطلبة } & \multirow[t]{2}{*}{ المجموعة } \\
\hline المباشر & القبلي & المباشر & القبلي & & \\
\hline rז,r & $r, 1 \wedge$ & $11, \times 1$ & $1 \cdot, \cdots$ & rA & الضمابطة \\
\hline$r, \wedge \wedge$ & 1,09 & $10, \cdot v$ & $1 \cdot, 71$ & rA & التجريبية \\
\hline
\end{tabular}

و لاختبار دلالة هذه الفروق الظاهرية، استخدم

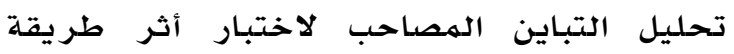

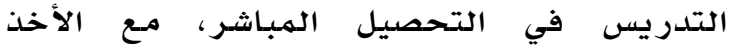

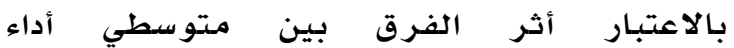
المجموعتين: التجريبية والضابطة في الاختبار القبلي، وجدول r يظهر تلك النتائج.

يتضح من جدول r ب وجود فرق دال إحصدائيا بين متتوسطي التحصيل البعدي المباشر للهـجموعتين: الضابطة والتجريبية في مبحث أسس الرياضيات

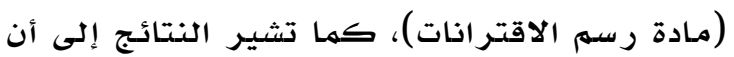

عر ضها في نتائج الدراسـة، ـيث استخدمت المتوسطات و الانحر افات المعيارية، وكذلك استخدم اختبار تحليل التباين المصاحب (ANCOVA).

\section{تصميم الدراسة}

التصميم المستخلدم في هذه الدر اسـة هو التصميم شبـه التجر يبي لمجمو عتين كما يلي:

$\begin{array}{lllll}\text { EG } & \mathrm{O} 1 & \mathrm{X} & \mathrm{O} 2 & \mathrm{O} 3\end{array}$

$\begin{array}{lllll}\mathrm{CG} & \mathrm{O} 1 & - & \mathrm{O} 2 & \mathrm{O} 3\end{array}$ حيث تشير : EG CG O1 التطبيق القبلي لاختبار التحصيل في وحدة رسم الاقتر انات لقياس التحصيل القبلي. X الهعالجة التجر يبية (التدريس باستخدام بر مجية رسهم الاقتر انات). O2 التطبيق البعدي لاختبار التحصيل في وحدة رسه الاقتر انات لقياس التحصيل البعدي الهباشر . O3: التطبيق البعدي لاختبار التحصيل في وحدة رسم الاقتر انات لقياس التحصيل البعدي المؤجل.

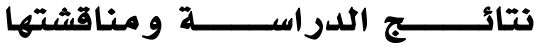

نتائج السؤال الأول: مـا أثر استخدام برمجية

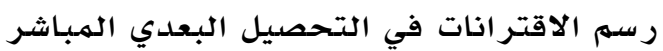

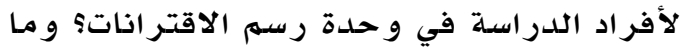
حجم الأثر إن وجدى الدره و لإججابة عن هذا السؤال حسبت المتوسطات

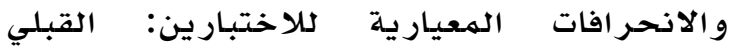

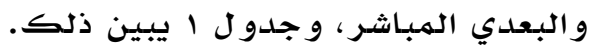

يلاحظ من جدول ا أن متوسط أداء الهـمهوعة

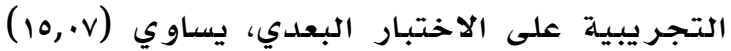

جدول

نتائج تحليل التباين المصاحب لعلامات الطلبة أفراد الدراسة على الاختبار البعدي المباشر في وحدة رسم الاقترانات

\begin{tabular}{|c|c|c|c|c|c|c|}
\hline حجم الأثر & الدلالة & قيمة (ف) & متوسط المربعات & الحرية & مجموع المربعات & مصدر التباين \\
\hline$\cdot, r \leq \wedge$ & $\cdot, \cdots$ & $|V, \varepsilon \wedge|$ & $1 \vee 0, \Sigma 97$ & 1 & $1 \vee 0, \leqslant 97$ & المتغير المصاحب (القبلي) \\
\hline \multirow[t]{3}{*}{$\cdot, 174$} & $\cdot, \cdot r$ & $1 ., 0 Y 9$ & $1 \cdot 0, v \cdot 7$ & 1 & $1 \cdot 0, v \cdot 7$ & طريقة التدريس \\
\hline & & & $1 \cdot, \cdot r q$ & or & Orr,.VO & الخطأ \\
\hline & & & & 00 & $\wedge T 0$, rov & الكلي المعدل \\
\hline
\end{tabular}


القول إن استر اتيجية تعلهم رسم الاقتر انات

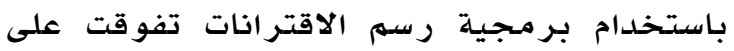
الطريقة التقليدية من حيث التحصيل المباشر لأَفر اد الدر اسـة.

ويمكن أن تعزى هذه النتيجة إلى ما تتصف بـه

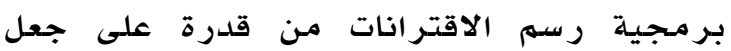
المتعلهم نشطا و فاعلا أثناء اكتسابه الهمارات في تعلمهـ، و كذلك لطبيعة البرمجية في عرض البه الأمثلة وتقديمها، فهي تقدم الهعطيات بديناميكية وحيوية، ما يمنح الطالب فرصدة كافية لمعالجة

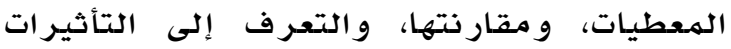
التي مـن الهمكن أن تقع على منـحنى الاقتر ان من

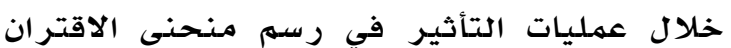
.(Scaling \& Rigid transformations) تشهل عمليات التأثير تلك أربع عمليات هي: الإزاحة: Transition والانعكاس: Reflection و الضغط: Compression و المط: Stretch، فمن خلال تطبيق الطالب لهذه العمليات على دالة

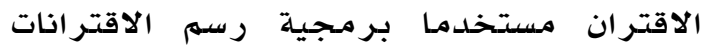
يكتشف تأثير ها في منحنى الاقتران (FooPlot)

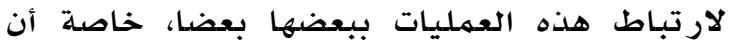

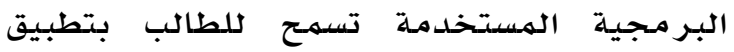
جميع العمليات السابقة في مستوى إحداثيات و احلد، و كلاقتر ان نفسـه؛ ما يسيهل على الطالب فهمه العمليات السابقة، و المقارنة بينها، و يوضح شكل r مثالا على تطبيق عمليات التأثير الأربع ولئ
قيمة ف لأثر الهعالجة وفقا لطريقة التدريس

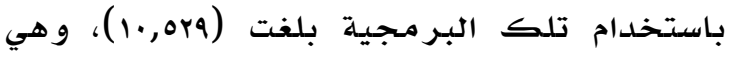
دالة إحصائيا عند مستوى دلالة (ه.,.) لصالح المسجمو عة التجر يبية.

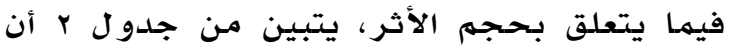

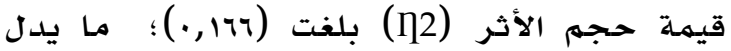
على أن نسبة التباين المفسر من قبل طريقة

$$
\text { التدريس هي (7,7) (17). }
$$

لتحديد لصالح من كانت تلك الفروق، حسبت المتوسطات المعدلة والخطأ المعياري المقابل لها

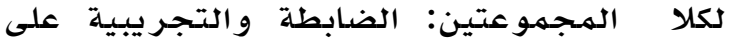
الاختبار البعدي المبـاشر، وجدول لم يوضيح ذلك:

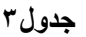

المتوسطات الحسابية المعدلة للمجموعتين الضابطة والتجريبية

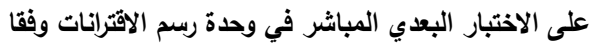

\begin{tabular}{|c|c|c|}
\hline \multicolumn{3}{|c|}{ لطريقة التدريس. } \\
\hline الخطأ المعياري & المعدل & المجموعة \\
\hline$\cdot, 7 \cdot r$ & $1, \ldots 1$ & الضابطة \\
\hline$\cdot, T \cdot r$ & $1 \varepsilon, \vee \wedge 0$ & التجريبية \\
\hline
\end{tabular}

تشير البيانات الواردة في جدوله إلى أن قيمة

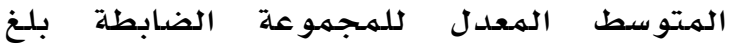

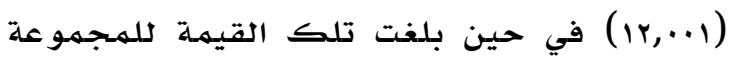
التجريبية ( للهتوسطات الهعدلة أن الهتوسط الهعدل

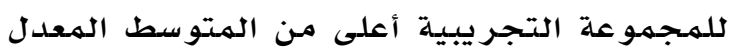

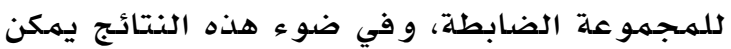
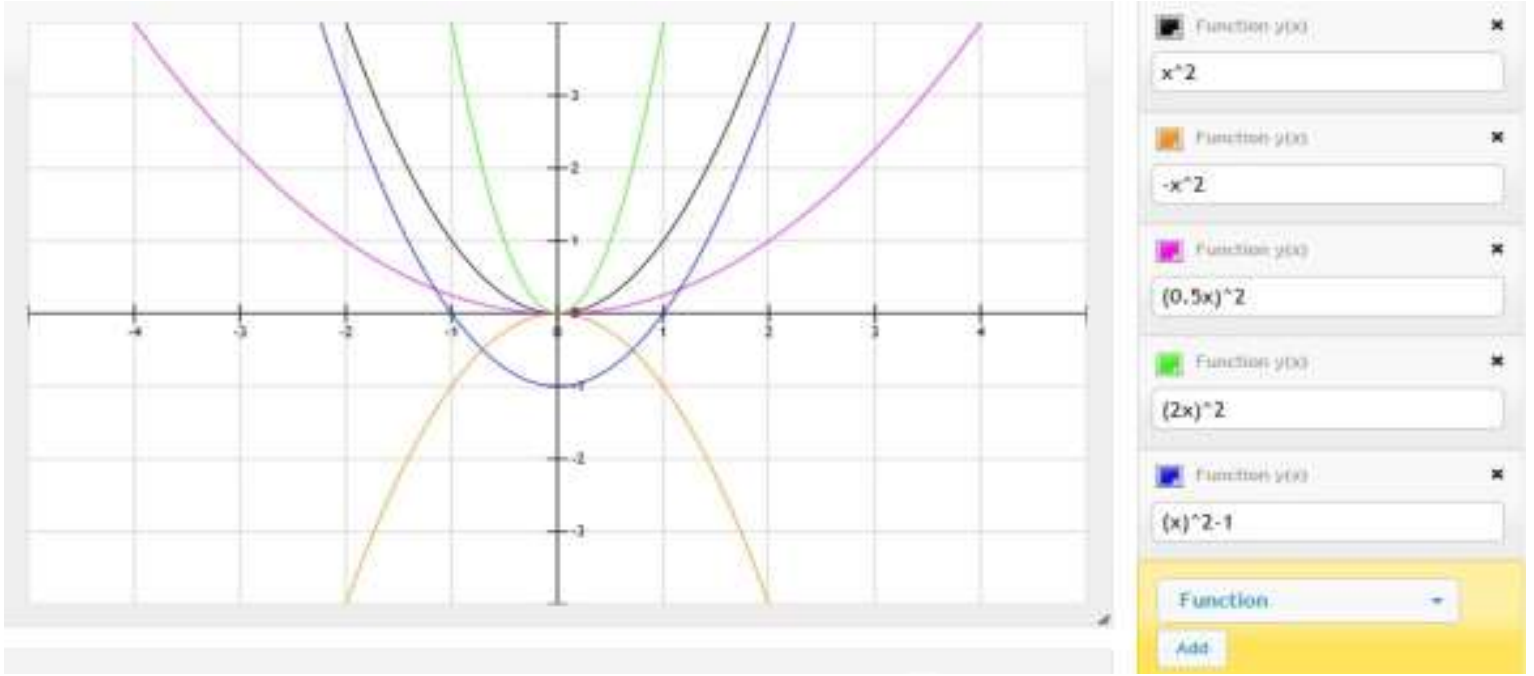

شكل r: شاشة عرض برمجية (FooPlot) ويظهر فيها منحنى الاقتران الأصلي y=f(x)=x^2 باللون الأسود، أما المنحنى باللون الأصفر فيتأثر بعملية

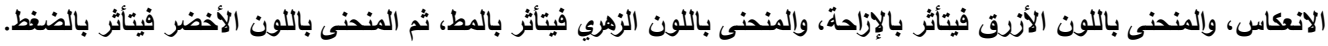


درجة، و وتدل هذه النتيجة الوصفية على وجود

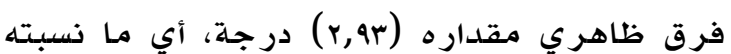

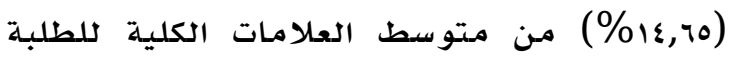

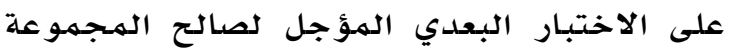

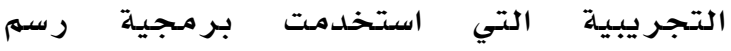
الاقتر انات.

لاختبار دلالة الفروق الظاهرية آنفة الذكر،

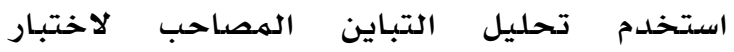
التحصيل المؤجل كما هو مـوضتح في جدول ه: يتضح من جدول ه وجود فرق دال إحصائيا بين متوسطي التحصيل المؤجل للمهجمو عتين: الضابطة والتجريبية في مبحث أسس الرياضيات

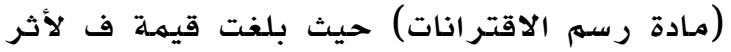

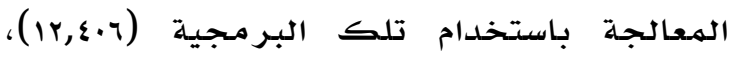

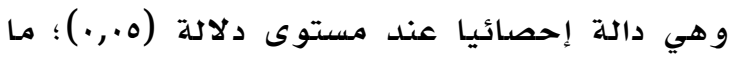
يدل على و وجود فرق بين متوسطي أداء المجمموعتين: التجريبية والضدابطة على الاختبار المؤجل لصالح الهمجموعة التجرئية.

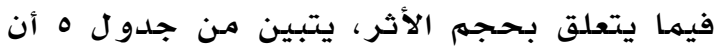

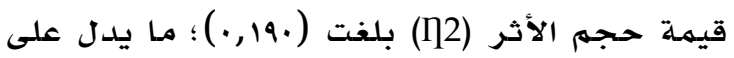
أن نسبة التباين الهفسر من قبل طريقة التدريس

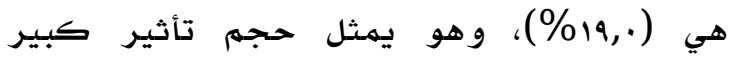
(منصور، (199V). (مئ)

لتحديد لصالح من كانت تلك الفروق، حسبت المتوسطات المعدلة والخطأ الهمياري الهقابل لها ملها

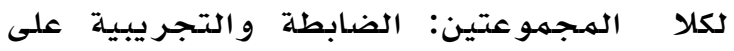
الاختبار البعدي المؤجل، وجدول

ذلك:
سابقة الذكر في دالة الاقتران نفسها، وهي

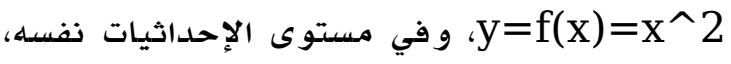

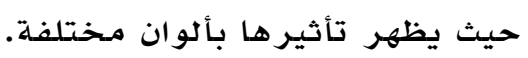

\section{نتائج السؤال الثاني}

ينص السؤال الثاني على الآتي: ما أثر استخدام

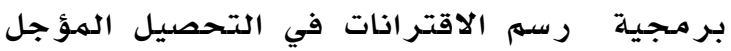
لطلبة السنـة الأولى في وحدة رسم الاقتر انات؟ و ما حجم الأثر إن وجله الأوى

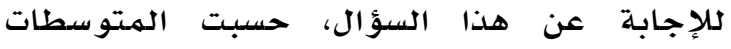

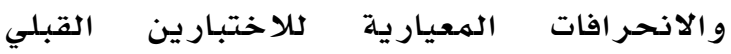
و البعدي الهؤجل، كما هو مبين في جدول ع. جدول ؛

المتوسطات الحسابية والانحرافات المعيارية للعلامات الكلية لأفراد

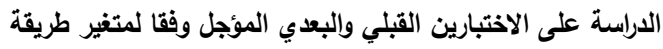
التدريس(الطريقة الاعتيادية، التدريس ببرمجية رسم الاقترانات)

\begin{tabular}{|c|c|c|c|c|c|}
\hline \multicolumn{2}{|c|}{ الانحراف المعياري } & \multicolumn{2}{|c|}{ المتوسطات من } & \multirow{2}{*}{ علد } & \multirow[t]{2}{*}{ المجموعة } \\
\hline المؤجل & القبلي & المؤجل & القبلي & & \\
\hline$r, \wedge r$ & $r, 1 \wedge$ & $1 \cdot, \mathrm{V}_{0}$ & $1 \cdot, \cdots$ & rA & الضابطة الهموعة \\
\hline$r, r_{1}$ & 1,09 & 1r, & $(\cdot, 7)$ & $\mathrm{r}^{\prime}$ & التجريبية \\
\hline
\end{tabular}

يلاحظ من جلدول ع أن المتوسط للعلامـات الكلية

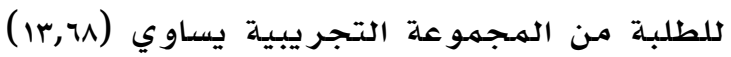

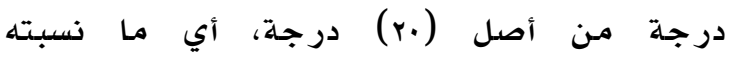

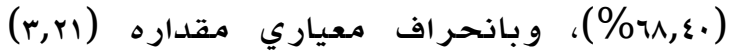

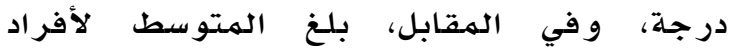
الهمجموعة الضابطة على الاختبار نفسه $(1$, (1)

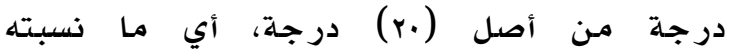

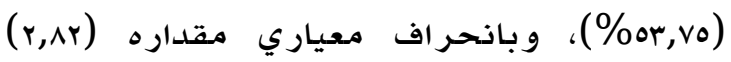

جدول

نتائج تحليل التباين المصاحب لعلامات الطلبة أفراد الدراسة على الاختبار البعدي المؤجل في وحدة رسم الاقترانات

\begin{tabular}{|c|c|c|c|c|c|c|}
\hline حجم الأثر & مستوى الدلالة & قيمة (ف) & منوسط المربعات & درجات الحرية & مجموع المربعات & مصدر التباين \\
\hline דזr, & $\cdot, \cdots$ & $r q, Y V_{0}$ & $170,01 \mathrm{~V}$ & 1 & $170,01 \mathrm{~V}$ & المتغير المصاحب(القبلي) \\
\hline \multirow[t]{3}{*}{$\cdot, 19$} & $\cdot, \cdots 1$ & $1 Y, \varepsilon \cdot T$ & VI, VYT & 1 & VI, VYr & طريقة التدريس \\
\hline & & & $7,1 \wedge \varepsilon$ & or & TrV,VV. & الخطأ \\
\hline & & & & 00 & $\Upsilon 1 \Gamma, \leqslant Y q$ & الكلي المعدل \\
\hline
\end{tabular}


للوقت في رسهم أنواع كثيرة لهنحنيات

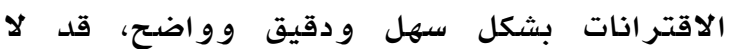
يحصل عليها بالطريقة التقليدية لرسمر منحنيات

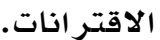

الجدير بالذكر أن بعض منحنيات الاقترانات

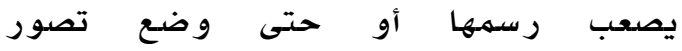

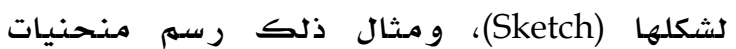
الاقتر انات المثلثية (Trigonometric Functions) وخاصة عندما تكون الزاوية عشرية، ففي مثل هذه الاقتر انات تتشكل لدينا- أثناء الر سهر- منطقة

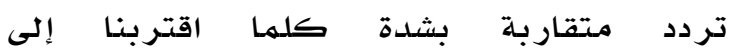

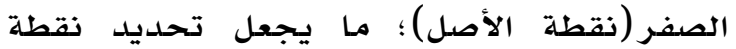
البدء للرسهم أو اختيار الزوايا للتمثيل عملية

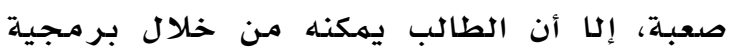
رسهم الاقترانات المستخدمة البدء من أي نقطة

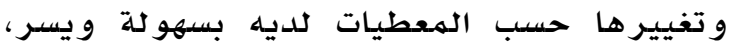

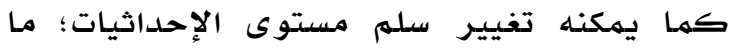
يكشف له سلوك منحنى الاقتران في منطقة

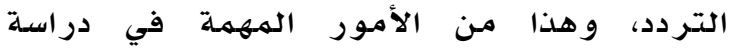

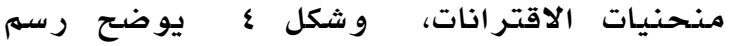
منحنى الاقتران لs=f(x)=sin(x) باللون الأزرق، و منطقة تردد بلدرجة عالية حول الصفر

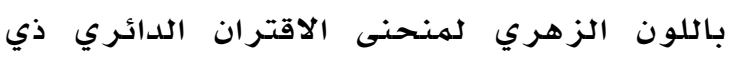
الز اوية العشرية (1/x)
جدول 1 المتوسطات المعلة لأداء المجموعتين الضابطة والتجريبية على

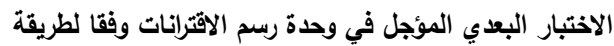

\begin{tabular}{ccc}
\multicolumn{3}{c}{ المجموعة } \\
\hline الضابطة \\
\hline التجريبية
\end{tabular}

يتضح من جلدول 1 أعلاه أن قيمة الهتوسط

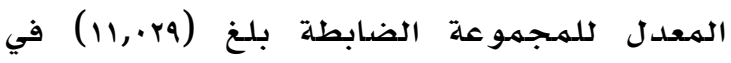
حين بلغت تلك القيهـة للمجهموعة التجريبية

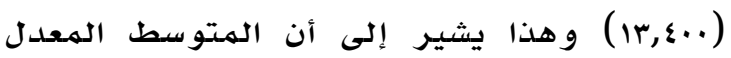

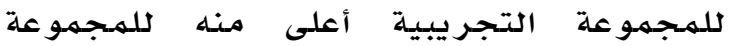

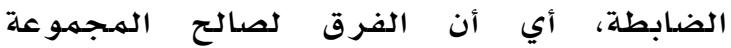

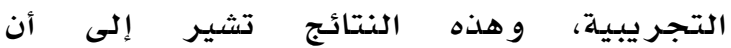
استراتيجية تعلهم رسم الاقتر انات- باستخدام بر مجية رسم الاقتر انات- تفوقت على الطريقة التقليدية من ميث التحصيل المؤجل لأفراد

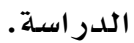

يمكن أن تعزى هذه النتيجة إلى أن البرهـية

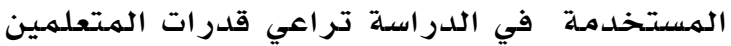

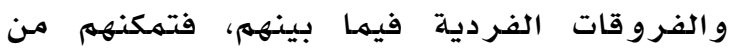
التعلهم وفقا لما تسهـح به قدراتهم، فيبقي تأثير

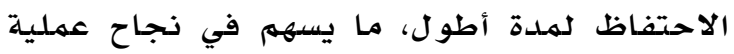
التعلهم وزيادة فاعليتها. كما يمكن أن يعزى النى الأثر الإيجابي للبر مجية المستخدمة إلى الإثارة التي تتركها أثناء عملية التعلهم، ووفي توفيرها

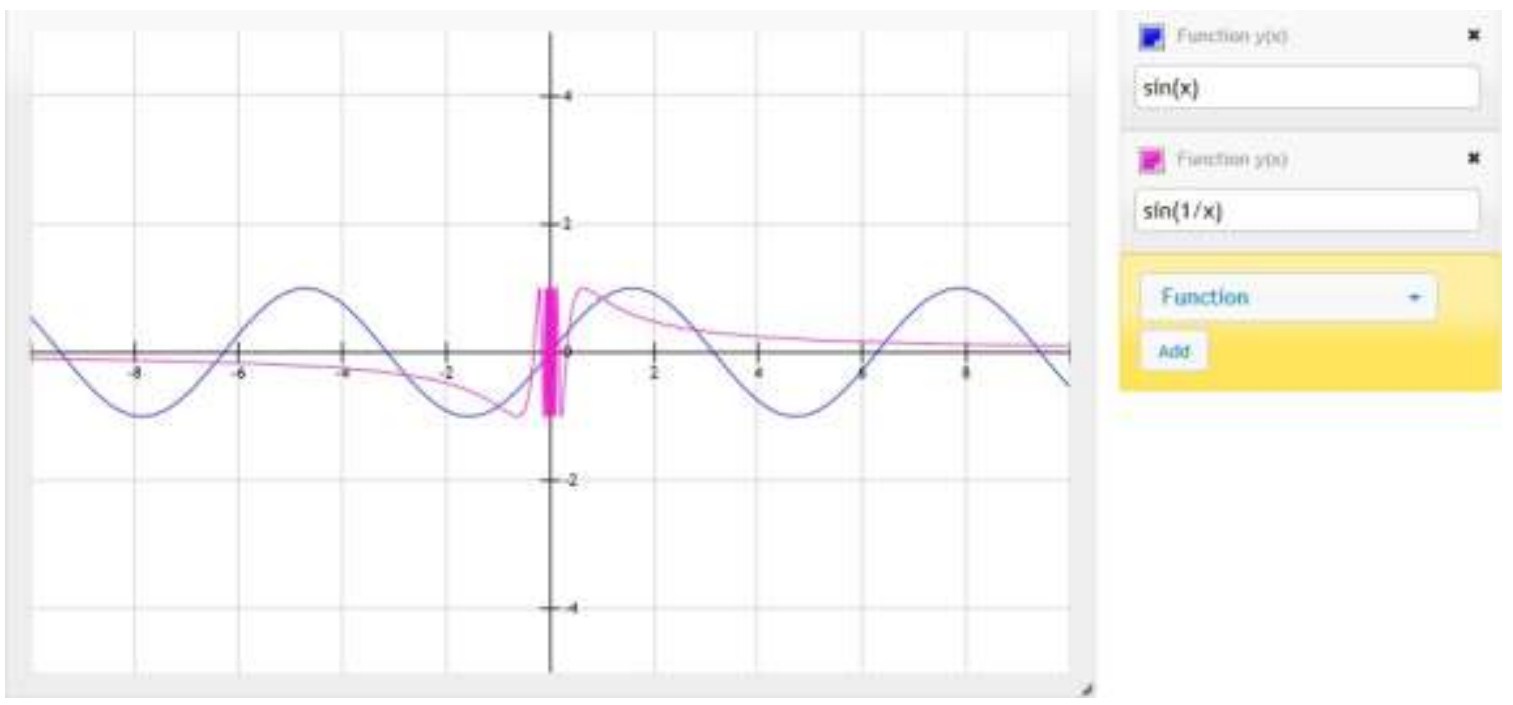

شكل ؛ : شاشة عرض برمجية (FooPlot) ويظهر فيها منحنى الاقتران (y=f(x)=sin(x) باللون الأزرق، ومنحنى الاقتران (1/x)=s(x)=sin باللون الزهري ذي التردد حول الصف 


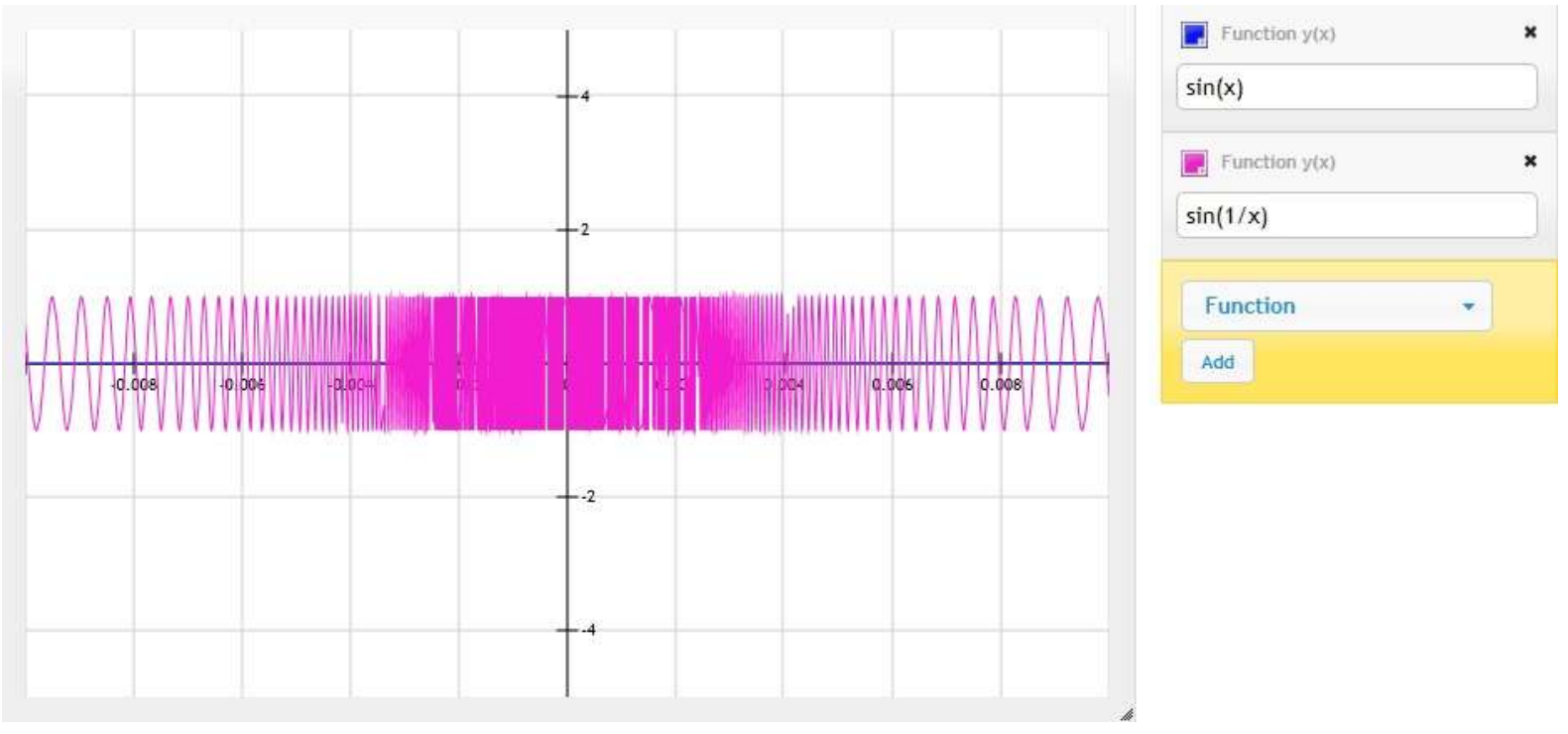

شكل ه: شاشة عرض برمجية (FooPlot) ويظهر فيها منحنى الاقتران (x=f(x)=sin(1/x) باللون الزهري ذو التردد المتزايد كلما اقترينا إلى الصفر، أما منحنى الاقتران (y=f(x)=sin(x) باللون الأزرق فلم يعد يظهر بسبب تغيير سلم مستوى الإحداثيات

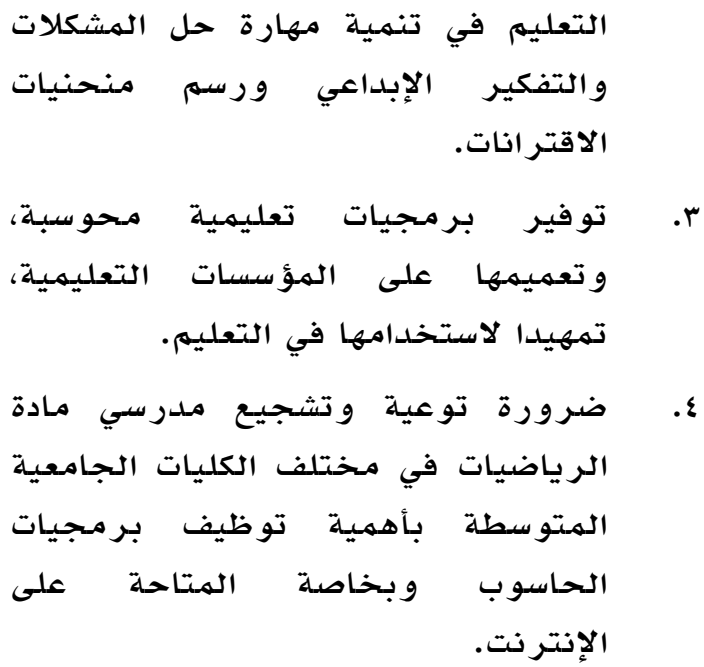

\section{المر اجع}

\section{References}

أبو لبدة، خطاب (r..v). التقرير الوطني الأردني عن الدراسة الدوولية للرياضيات و العلوم لعام

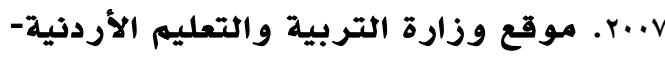

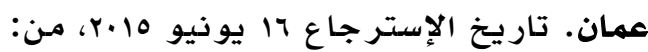
http:/ / www.moe.gov.jo/Files/(14-32011)(2-11-40\%20PM).pdf بدر، بثينة (l+r). أثر استخدام الحاسوب في التدريب على حل المشكلات الرياضية في تنمية قدرة طالبات قسم الرياضيات بكلية التربية بمكة المكرمة على حل هذه المشكلات وتكوين اتجاه إيجابي نحو الرياضيات
ما شكل ه فيبين كيف أن التغيير في سلهم مستوى

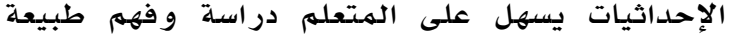

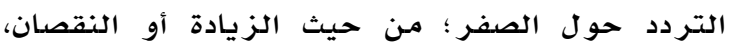
وون حيث أن الاقتران متصل أم أنه منفصل.تتفق نتيججة هذه الدراسـة مـع نتائج دراسلة كل من:

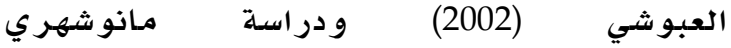

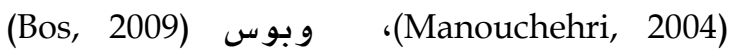
و هيان و آخرين (Haiyan et al, 2010) التي أثارت إلى أن استخدام برمجيات الحاسوب في تعليهم الرياضيات يرفع مستوى تحصيل الطلبة فيها. تختلف هذه النتيججة مـع نتيجة دراسـة ساكاموتو و ساكامـو تو (Sakamoto \& Sakamoto, 1993) التي هذه أظهرت عدم و جود أثر دال إحصائيا بين استخدام الحاسوب من جهة ، وبين تحصيل الطلبة أو دافعيتهم للتعلهم من جهة أخرى.

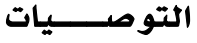

في ضوء نتائج الدراسـة، يمكن تقديم التوصيات والمقتر حات الآتية:

1. تفعيل استخدام البر مجية التعليمية الهستخدمة في هذه الدر اسلة، لها أظهر ته من أثر إيجابي في تحسين تحصيل الطلبـة المباشر و المؤجل. r. إجراء المزيد من الدراسـات التي تبحث في أثر استخدام بر مجيات الحاسوب في 
Bos, B. (2009). Virtual math objects with pedagogical, mathematical, and cognitive fidelity. Computers in Human Behavior, 25, 521-528.

Eid, G. (2005). An investigation into the effect factors influencing Computers-based online math problem solving in primary schools. Journal of Educational Technology Systems, 33(3), 223-240.

Haiyan, B., Atsusi, H., \& Mansureh, K. (2010). The Effects of Modern Mathematics Computer Games on Mathematics Achievement and Class Motivation. Computers E Education, 55(2), 427-443.

Kurtulus, A., \& Uygan, C. (2010). The effects of Google Sketchup based geometry activities and projects on spatial visualization ability of student mathematics teachers. Procedia-Social and Behavioral Sciences, 9, 384-389.

Manouchehri, A. (2004). Using interactive algebra software to support a discourse community.The Journal of Mathematical Behavior, 23(1), 37-62.

National Council of Teachers of Mathematics (NCTM). (2000). Principles and Standards for School Mathematics. Reston, VA: NCTM.

National Council of Teachers of Mathematics (NCTM). (2008). The Role of Technology in the Teaching and Learning of Mathematics. Retrieved on August 15, 2014 from:

$\underline{\text { http:// standards. nctm. org/document/ }}$ index. htm.

Sakamoto, A., \& Sakamoto, T. (1993). Causal relationships between computer use, creativity, and motivation for learning in children: A panel survey of male elementary school students. Educational technology research, 16, 1-10.

Seo, J. (2008). Effects of multimedia software on word problem-solving performance for students with mathematic difficulties ( $\mathrm{PhD}$ Dissertation). University of Texas, Austin. 3324680 .

Wei, C., \& Ismail, Z. (2010). Peer Interactions in Computer-Supported Collaborative Learning using Dynamic Mathematics Software. International Conference on Mathematics Education Research.Malaysia.

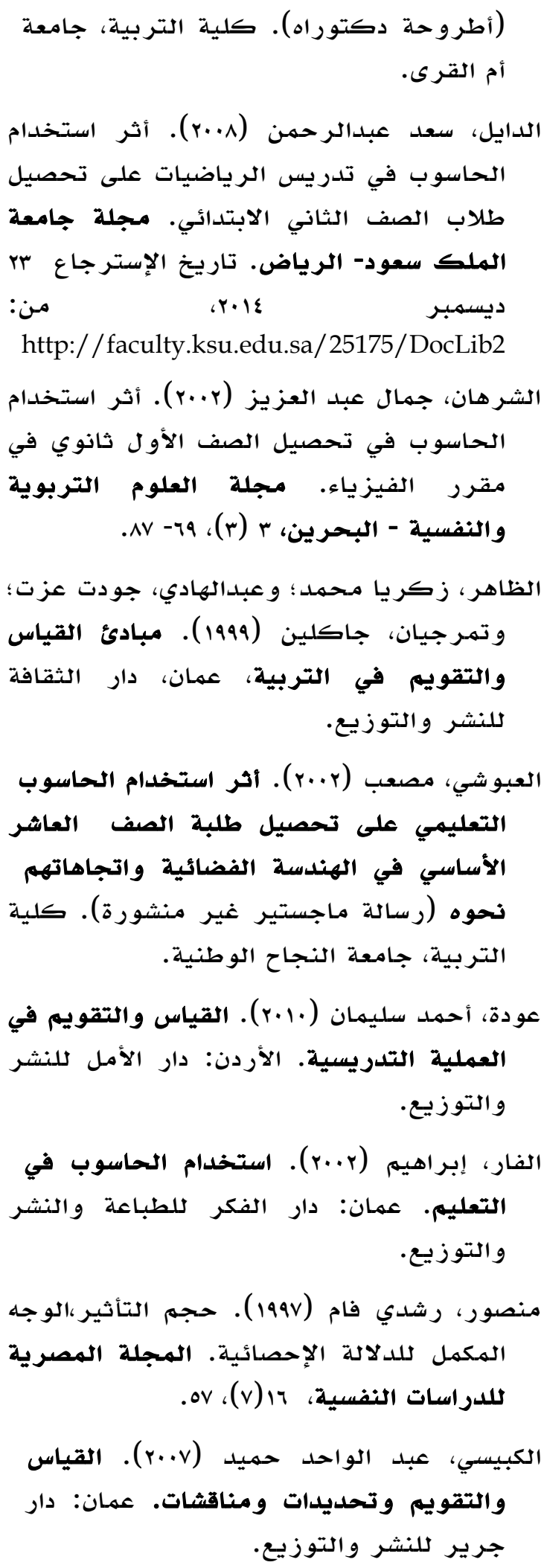

